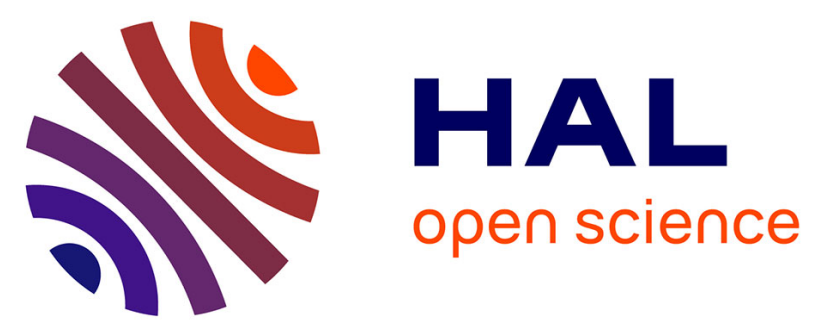

\title{
Iron(II) complexes with diazinyl-NHC ligands: impact of $\pi$-deficiency of the azine core on photophysical properties
}

Mohamed Darari, Edoardo Domenichini, Antonio Francés-Monerris, Cristina Cebrian, Kevin Magra, Marc Beley, Mariachiara Pastore, Antonio Monari, Xavier Assfeld, Stefan Haacke, et al.

\section{To cite this version:}

Mohamed Darari, Edoardo Domenichini, Antonio Francés-Monerris, Cristina Cebrian, Kevin Magra, et al.. Iron(II) complexes with diazinyl-NHC ligands: impact of $\pi$-deficiency of the azine core on photophysical properties. Dalton Transactions, 2019, 48 (29), pp.10915-10926. 10.1039/c9dt01731c . hal-02145893

\section{HAL Id: hal-02145893 \\ https://hal.science/hal-02145893}

Submitted on 5 Oct 2021

HAL is a multi-disciplinary open access archive for the deposit and dissemination of scientific research documents, whether they are published or not. The documents may come from teaching and research institutions in France or abroad, or from public or private research centers.
L'archive ouverte pluridisciplinaire HAL, est destinée au dépôt et à la diffusion de documents scientifiques de niveau recherche, publiés ou non, émanant des établissements d'enseignement et de recherche français ou étrangers, des laboratoires publics ou privés. 


\title{
Iron (II) complexes with diazinyl-NHC ligands: Impact of $\pi$ - deficiency of the azine core on photophysical properties
}

\author{
Mohamed Darari, ${ }^{a}$ Edoardo Domenichini, ${ }^{b}$ Antonio Francés-Monerris, ${ }^{c}$ Cristina Cebrian, ${ }^{d}$ Kevin \\ Magra, ${ }^{d}$ Marc Beley, ${ }^{a}$ Mariachiara Pastore, ${ }^{c}$ Antonio Monari, ${ }^{c}$ Xavier Assfeld, ${ }^{c}$ Stefan Haacke ${ }^{b}$ and \\ Philippe C. Gros*,a
}

Ligand field enhancing N-heterocyclic carbene (NHC) ligands were recently shown to prevent photo-induced spin crossover in $\mathrm{Fe}$ (II) complexes due to their intricate effects on the electronic excited state structure. Due to their pico- to nanosecond lifetimes, these complexes are now good candidates for photo-sensitizing applications. Herein we report the synthesis and photophysical characterization of a new family of homoleptic $\mathrm{Fe}(\mathrm{II})$ complexes with $\mathrm{C}^{\wedge} \mathrm{N}^{\wedge} \mathrm{C}$ ligands involving diazines as the central $\mathrm{N}$-heteroaromatic ligand. For these four carbene bonds complexes, ultrafast transient absorption spectroscopy revealed a significant improvement of the excited-state lifetime. A record 32 ps lifetime was measured for a complex bearing a ligand combining a $\pi$-deficient pyrazine nucleus and a benzimidazolylidene as NHC. When compared to other azine-based ligands investigated, we argue that the lifetimes are modulated by a small excited state barrier expressing the ability of the ligand to reach the $\mathrm{Fe}-\mathrm{N}$ distance needed for internal conversion to the ground state.

\section{Introduction}

Photoactive metal complexes play a pivotal role in several excitonic devices. ${ }^{1,2,3}$ Such applications require the smart design of ligands to finely control the optical and electrochemical properties of the metal complexes. Due to their optimal photophysical features, noble metals, such as ruthenium or platinum allows the design and fabrication of devices having impressive properties in terms of efficiency or tenability. ${ }^{4,5}$ However, such success comes with a price to pay; notably the low abundance, relatively high cost and toxicity of such metals, that may strongly limit their employment in larger scale industrial productions. Thus, finding alternative routes, by using less toxic and more abundant metals such as iron, would highly reduce the cost and the environmental impact of manmade technology. However, the fine control of the photophysical behaviour of first-row transition metal complexes is particularly challenging. Indeed, and as a most significant example, while the excited state evolution of ruthenium (II) polypyridyl complexes is dominated by longlived metal-to-ligand (MLCT) triplet states, ${ }^{6}$ a sub picosecond relaxation to metal centred (MC) states followed by an ultrafast ground-state recovery is observed for the iron analogues. ${ }^{7,8,9,10}$ Most notably, this ultrafast non-radiative deactivation, is the main reason precluding the successful utilization of iron complexes in photochemical applications requiring stabilized MLCT states, such as dye sensitizes solar cells (DSSCs), ${ }^{5}$ or in emissive devices.

Recently, several groups have raised the challenge and proposed the design of photoactive iron complexes by increasing the ligand field splitting with the aim to destabilize the metal centred states. ${ }^{11}$ In this context, a considerable breakthrough has been achieved using pyridyl N-heterocyclic carbenes (NHC) as ligands combining the $\pi$-deficiency of pyridine and the $\sigma$-donating property of NHC. ${ }^{12,13}$ Indeed, excited-state lifetimes of tens of picoseconds, have been obtained for iron (II) complexes with tridentate $e^{14,15}$ and bidentate ${ }^{16,17}$ pyridyl-NHC ligands.

The influence of the conjugation pattern and peripheral substituents on the electronic properties of NHC has also been investigated by switching from imidazolylidene to benzimidazolylidene (BIm) or modifying the alkyl chain showing a notable improvement of the MLCT lifetime. ${ }^{14}$ In contrast, the effect of the nature of the central azine core has not been investigated yet, while the increase of its $\pi$-deficiency might be a promising route to promote an additional stabilization of the MLCT states when combined with the NHC-induced destabilization of the MC states.

In this contribution we report the synthesis of new diazinylNHC ligand precursors L1-L5 containing $\pi$-deficient pyrazine and pyrimidine and their corresponding iron (II) complexes C1C4. The excited-states decay of the organometallic complexes was characterized by ultrafast time-resolved spectroscopy and by modelling the potential energy surfaces (PESs) via timedependent density functional theory (TD-DFT). 


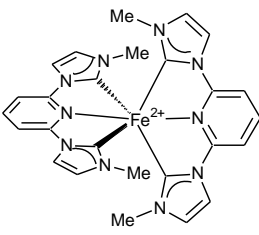

co

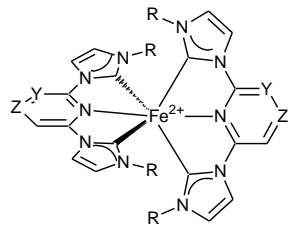

C1, $\mathrm{Y}=\mathrm{CH}, \mathrm{Z}=\mathrm{N}, \mathrm{R}=\mathrm{Me}$ C2, $Y=C H, Z=N, R=H e x$

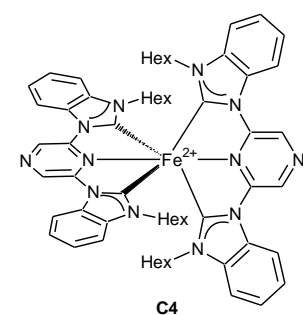

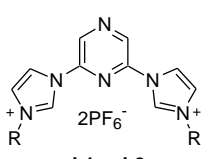

L1 or L2
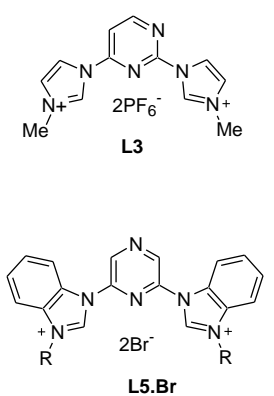

L5.Br

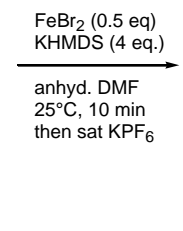

1) LiHMDS (2 eq) anhyd. THF $-10^{\circ} \mathrm{C}, 30 \mathrm{~min}$

2) $\mathrm{FeBr}_{2}(0.5$ eq. $25^{\circ} \mathrm{C}, 16 \mathrm{~h}$ then sat $\mathrm{KPF}_{6}$ then $25^{\circ} \mathrm{C}, 1 \mathrm{~h}$
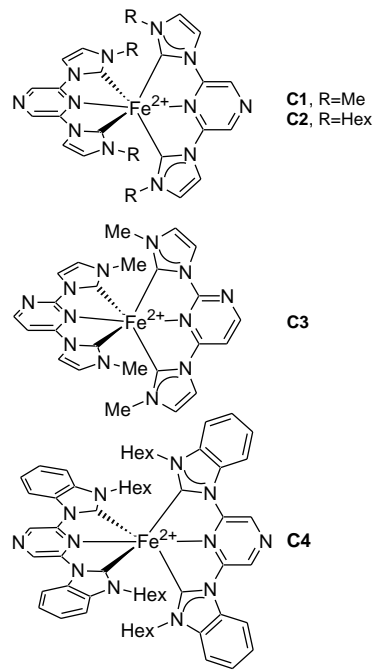

The ligand precursors L1-L5 required for the preparation of the target complexes have been obtained in good yields from both dichloro pyrazine and pyrimidine according to Scheme 1 . The ligands have been designed bearing short and long alkyl chains and different counter-anions to anticipate solubility concerns as well as anion effects along the coordination process with iron (II). ${ }^{18,19}$
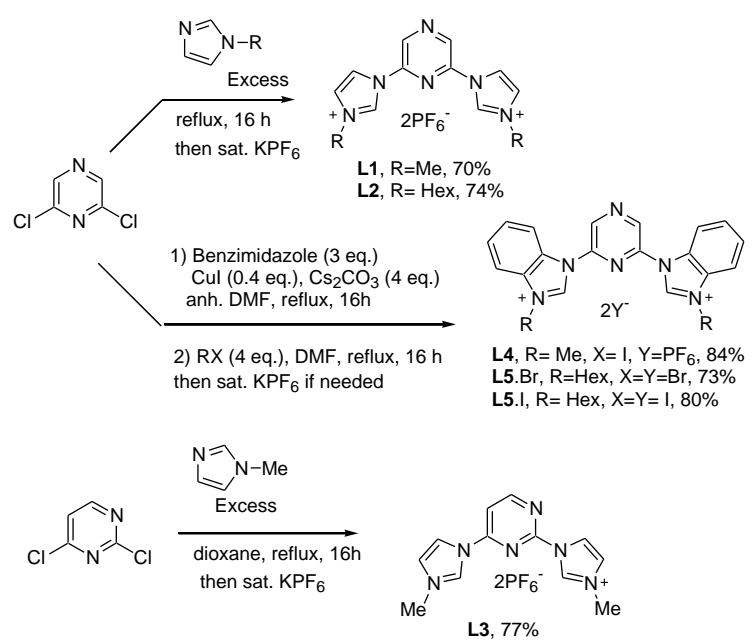

Scheme 1. Synthesis of ligands L1-L5

The coordination of the new ligands with iron (II) to obtain the complexes C1-C4 is performed as reported in Scheme 2. The ligands $\mathbf{L 1}, \mathbf{L 2}$ and $\mathbf{L 3}$ were reacted with a mixture of $\mathrm{FeBr}_{2}$ and hexamethyldisilazide (KHMDS) leading to the target complexes $\mathbf{C 1}, \mathbf{C 2}$ and $\mathbf{C 3}$ respectively. The process used above was not effective for the synthesis of $\mathbf{C 4}$. In this case, the carbene was first generated by initial deprotonation of L5.Br by LiHMDS followed by reaction with $\mathrm{FeBr}_{2}$. In this case, due to solubility issues, only the ligands bearing the hexyl chain led to the expected complex $\mathbf{C 4}$.
Scheme 2. Synthesis of Complexes C1-C4

\section{Electronic and electrochemical properties}

The electronic properties of the complexes C1-C4 were preliminary investigated by means of steady-state UV-vis spectroscopy (Figure 2) and cyclic voltammetry (Table 1). The data related to complex $\mathbf{C O}$ have been also included for the sake of comparison.

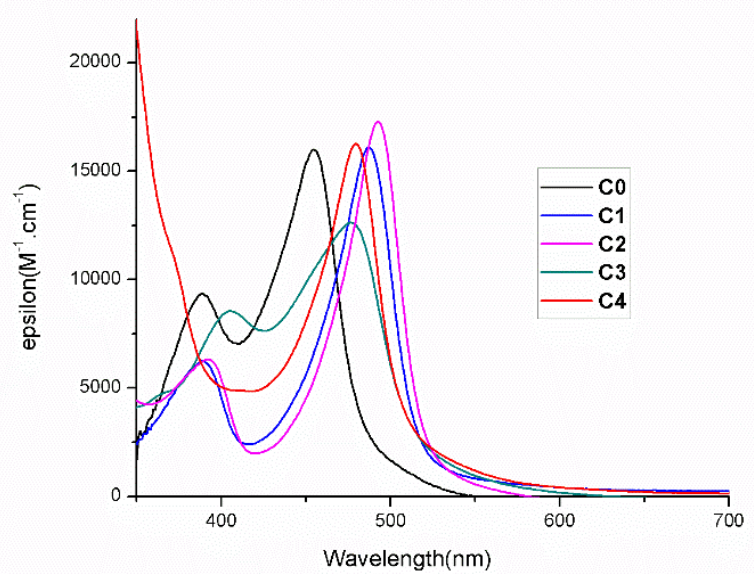

Figure 2. UV-Vis spectra of CO-C4 in acetonitrile. The portion of the spectrum below $350 \mathrm{~nm}$ is not shown due to intense UV bands in case of C4.

For all the complexes, the absorption spectra are composed of three bands. Intense band in the UV region and below $350 \mathrm{~nm}$ (not shown here) corresponds to $\pi-\pi^{*}$ transitions centred on the ligands, and as expected, they are much more intense for $\mathbf{C 4}$ bearing the four BIm moieties.

At longer wavelengths, all the complexes exhibit two distinct bands associated to MLCT transitions and presenting significant shifts and changes in the band-shape as a function of the ligands. The bands in the $360-420 \mathrm{~nm}$ range are related to carbene-Fe MLCT transitions ${ }^{14}{ }^{20}$ while the bands in the 430 $600 \mathrm{~nm}$ area are due to the azine-Fe MLCTs. As a general trend, a notable red-shift of $30-40 \mathrm{~nm}$ of the azine-Fe band as compared to $\mathbf{C O}$ was observed for all the new complexes. This observation is in full agreement with the increased $\pi$-deficiency 
of the central azine when switching from pyridine to pyrazine and pyrimidine. Furthermore, BIm promotes a blue shift of both azine-Fe and carbene-Fe transitions, as can be noticed by comparing the absorption spectra of $\mathbf{C 1}$ and $\mathbf{C 4}$, as a result of an increased $\pi$-back donation from the metal, thus stabilizing the occupied iron $t_{2 \mathrm{~g}}$ orbitals and as a consequence the ground state. ${ }^{14}$ While the carbene-Fe transition was not affected when going from pyridine to pyrazine (compare $\mathbf{C 0}, \mathbf{C 1}$ and $\mathbf{C 2}$ ), the use of pyrimidine as the central azine induced a non-negligible red-shift of $30 \mathrm{~nm}$, and a general broadening of the 430-600 nm band, with the appearance of a broader shoulder around 450 $\mathrm{nm}$. This may be due to the reduced point group symmetry of C3 as compared to the other complexes.

Table 1. Photophysical and electrochemical properties of complexes

\begin{tabular}{|c|c|c|c|c|}
\hline & $\begin{array}{c}\lambda_{\text {abs-max }}(\mathrm{nm}) \\
\left(\varepsilon\left(\mathrm{M}^{-1} \cdot \mathrm{cm}^{-1}\right)\right)^{\mathrm{a}}\end{array}$ & $\begin{array}{c}\mathrm{E}_{o x} \\
\left(\mathrm{Fe}^{\mathrm{III}} / \mathrm{Fe}^{\mathrm{II}}\right) \\
(\mathrm{V} / \mathrm{SCE})^{\mathrm{b}}\end{array}$ & $\begin{array}{c}\mathrm{E}_{\text {redl }} \\
(\mathrm{V} / \mathrm{SCE})\end{array}$ & $\Delta \mathrm{E}(\mathrm{eV})^{\mathrm{c}}$ \\
\hline C0 & $\begin{array}{c}393(9000) \\
460(15900)\end{array}$ & 0.80 (rev) & -1.95 (irrev.) & 2.75 \\
\hline C1 & $\begin{array}{c}389(6300) \\
487(16100)\end{array}$ & 0.98 (rev) & -1.39 (rev) & 2.27 \\
\hline $\mathrm{C} 2$ & $\begin{array}{c}392(6200) \\
493(17300)\end{array}$ & 1.09 (rev) & -1.32 (rev) & 2.41 \\
\hline $\mathrm{C3}$ & $\begin{array}{c}406(8500) \\
477(12600)\end{array}$ & 0.93 (rev) & -1.70 (irrev) & 2.63 \\
\hline C4 & $\begin{array}{c}350(\mathrm{sh})(11000) \\
479(16200)\end{array}$ & $1.22(\mathrm{rev})$ & $-1.21(\mathrm{rev})$ & 2.43 \\
\hline
\end{tabular}

${ }^{a}$ Measured in $\mathrm{CH}_{3} \mathrm{CN}$ at $25^{\circ} \mathrm{C}$. ${ }^{\mathrm{b}}$ First oxidation potential. Potentials are quoted vs SCE. Under these conditions, $\mathrm{E}_{1 / 2}(\mathrm{Fc} / \mathrm{Fc})=0.39 \mathrm{~V} / \mathrm{S}$.C.E. Recorded in $\mathrm{CH}_{3} \mathrm{CN}$ using $\mathrm{Bu}_{4} \mathrm{~N}^{+} \mathrm{PF}_{6}$ $(0.1 \mathrm{M})$ as supporting electrolyte at $100 \mathrm{mV} . \mathrm{s}^{-1}$. ${ }^{\mathrm{c}}$ Electrochemical band gap $\left(\Delta \mathrm{E}=\mathrm{E}_{o x}-\right.$ $\mathrm{E}_{\text {red1 } 1}$ )

Figure S17 shows the TD-DFT spectra of $\mathbf{C 1}, \mathbf{C 2}, \mathbf{C 3}$ and $\mathbf{C 4}$. Even though the lowest-energy bands are blue shifted by around $0.3 \mathrm{eV}$ with respect to the experimental results, the trends described above are correctly reproduced by the computational protocol. The analysis of the natural transition orbitals (NTOs) ${ }^{21}$ further confirms the MLCT nature of the excitations involving the lowest-energy bands (see Figures S1820) and their assignment, whereas some contributions of interligand (IL) states are predicted for the intense band of $\mathbf{C 4}$ appearing at higher energies (see Figure S20).

The electrochemical profiles (Table 1) globally confirm the trends underlined by the absorption spectroscopy studies. Due to their higher $\pi$-deficiencies, pyrazine and pyrimidine promoted an increase of the $\mathrm{Fe}^{\mathrm{II}} / \mathrm{Fe}^{\mathrm{III}}$ oxidation potential as compared to $\mathbf{C 0}$, an effect that is even higher for $\mathbf{C 4}$ due to the electron-accepting effect of BIm .

The reduction potentials were also strongly affected and generally increased going from C0 to C4. Since reduction reflects the injection of one electron into the antibonding $\pi^{*}$ orbitals these results can, in a first approximation, be rationalized as a more efficient stabilization of the LUMO orbital by pyrazine than pyridine. However, $\mathbf{C 3}$ represents an exception to the trend, indeed the reduction potential was less significantly modified with respect to the other complexes.

\section{Ultrafast transient absorption spectroscopy}

In order to get further insights into the impact of the new ligands on the photophysical properties, the four complexes were investigated by femtosecond transient absorption spectroscopy (TAS) at room temperature. All samples are dissolved in $\mathrm{CH}_{3} \mathrm{CN}$ and excited at $480 \mathrm{~nm}$.

For C4, Figure $3 \mathrm{~A}$, three signals are observed, two positive bands (excited state absorption ESA) and one negative (ground state bleach GSB). Between such signals, two isosbestic points are identified at 428 and $500 \mathrm{~nm}$. The dot-dashed line corresponds to the inverse of the normalised steady-state absorption (SSA) scaled on the TA spectra at $484 \mathrm{~nm}$, the maximum of GSB. This spectrum has a perfect overlap with the TA-spectra in the range $440-491 \mathrm{~nm}$, while outside, the ESA signals are significantly adding up to the GSB, which implies a decrease of the GSB intensity. The positive bands have a different trend, indeed the blue one $(\lambda<428 \mathrm{~nm})$ does not present any time-evolution, in contrast to the redder one $(\lambda<500$ $\mathrm{nm}$ ), which can be split into two ranges: $500-590 \mathrm{~nm}$ where the intensity purely decays (shape conserved in time) while in the range $590-690 \mathrm{~nm}$ the spectra evolve within $\approx 1$ ps before

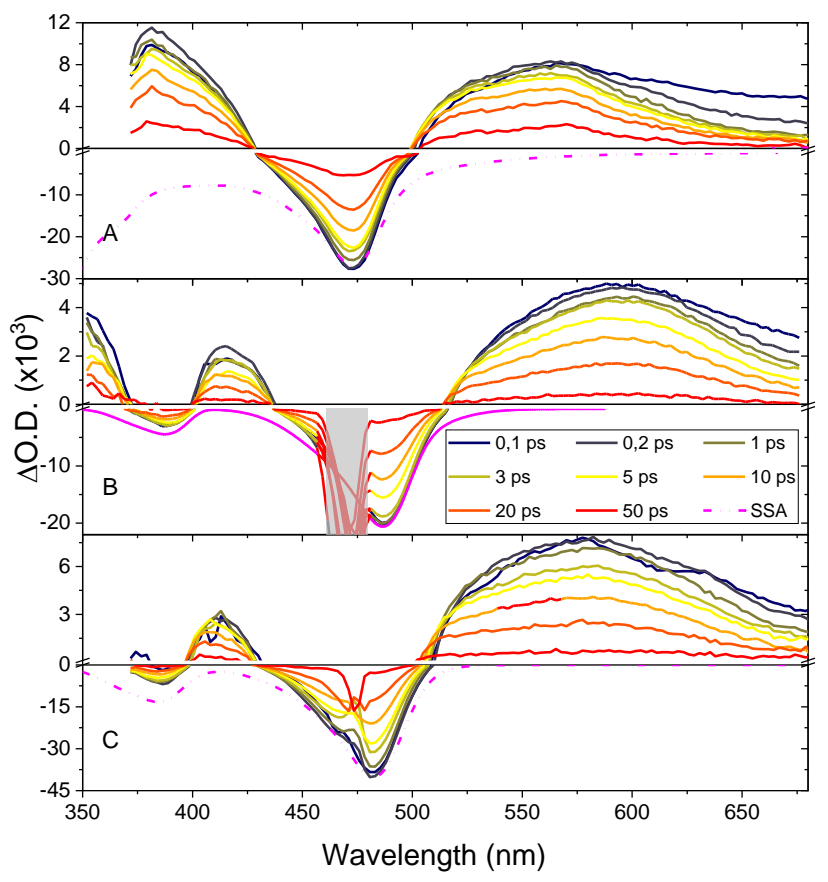

reaching a stable shape. This trend is highlighted in the spectra normalised at $473 \mathrm{~nm}$ (Fig SI 23).

Figure 3. Selected transient absorption spectra of C4 (A), C2 (B), C1 (C) in AcN excited at $480 \mathrm{~nm}$. Delay times are from $0.1 \mathrm{ps}$ (blue) to $50 \mathrm{ps}$ (red). Spectra of $\mathrm{C} 4$ and $\mathrm{C} 2$ display mainly intensity/exc. state population decay, while the spectra of $\mathrm{C} 1$ are subject to shifts and changes in shape until $\approx 20$ ps. Inverted steady state absorption (SSA) spectra are shown for comparison (dot-dashed pink line). Note different scale for positive and negative parts of $y$-axes. In B, grey shaded area denotes excessive pump beam scatter. 
All the spectra at $t>1$ ps overlay over the full wavelength range regions, while, at earlier times, a slight spectral evolution is visible.

In Fig 3B, selected spectra of $\mathbf{C 2}$ are shown. In variance with $\mathrm{C} 4$, two negative bands (GSB) are observed, peaking at 388 and $487 \mathrm{~nm}$, and three positives (ESA) at $\lambda<370 \mathrm{~nm}, 410$ and $578 \mathrm{~nm}$. Four isosbestic points are identified at $370,400,435$ and $516 \mathrm{~nm}$. The SSA, normalized at $487 \mathrm{~nm}$, overlaps perfectly in the red side of the main GSB $(\lambda>487 \mathrm{~nm})$ while, in the blue part $(\lambda<487 \mathrm{~nm})$, the intensity is $\approx 30 \%$ lower than the SSA. This small discrepancy, also in this case, points to an overlapping ESA at these wavelengths. The shape of the long-wavelength ESA presents a small evolution in time, which is better seen in Fig SI 25, where the normalized spectra show for the long-wavelength ESA, at $\lambda>525 \mathrm{~nm}$ narrowing, and a small dynamic shift. This causes the isosbestic point at $516 \mathrm{~nm}$ to shift by $\approx 5 \mathrm{~nm}$ in the first $20 \mathrm{ps}$.

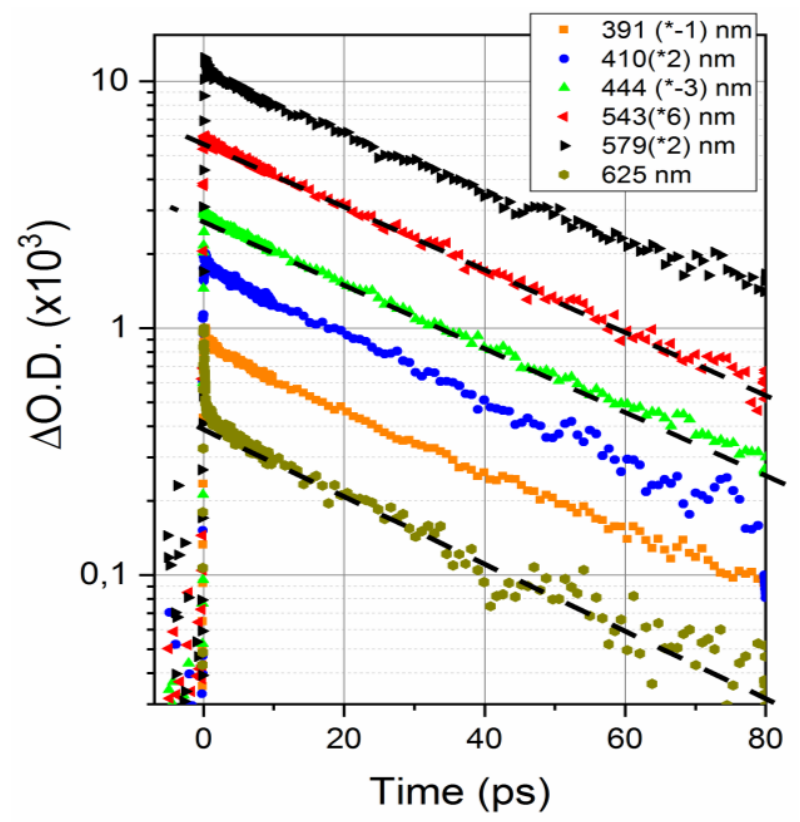

Figure 4. Selected kinetics of C4 plotted in semi-log scale. The kinetics are normalised and multiplied for an arbitrary factor as reported in the legend. For the GSB a negative factor is used. Dashed lines lines indicate the $\sim 30$ ps decay. Small deviations from the single exponential behaviour at early times relate to the minor spectral evolutions discussed in the text.

The kinetics of $\mathbf{C 4}$, at relevant wavelengths, are plotted in a semi-log scale and reported in Fig.4. They are normalised and multiplied by an arbitrary factor. The dashed lines highlight the mono-exponential decay associated with a lifetime of $\sim 30 \mathrm{ps}$ The kinetic traces are well approximated, on this time scale, by the mono-exponential decay, but some present small deviations i.e. additional short decay components at $\mathrm{t}<5$ ps with small amplitudes.

For C2, the kinetics are processed as before and plotted in Figure SI27. Most of the kinetics appear to be monoexponential, but for a precise analysis three lifetimes are necessary (see below). For $\mathbf{C 4}$ and $\mathbf{C 2}$, the minor dynamic shifts of the TA spectra are compatible with the use of a global fit approach. ${ }^{22}$ The obtained
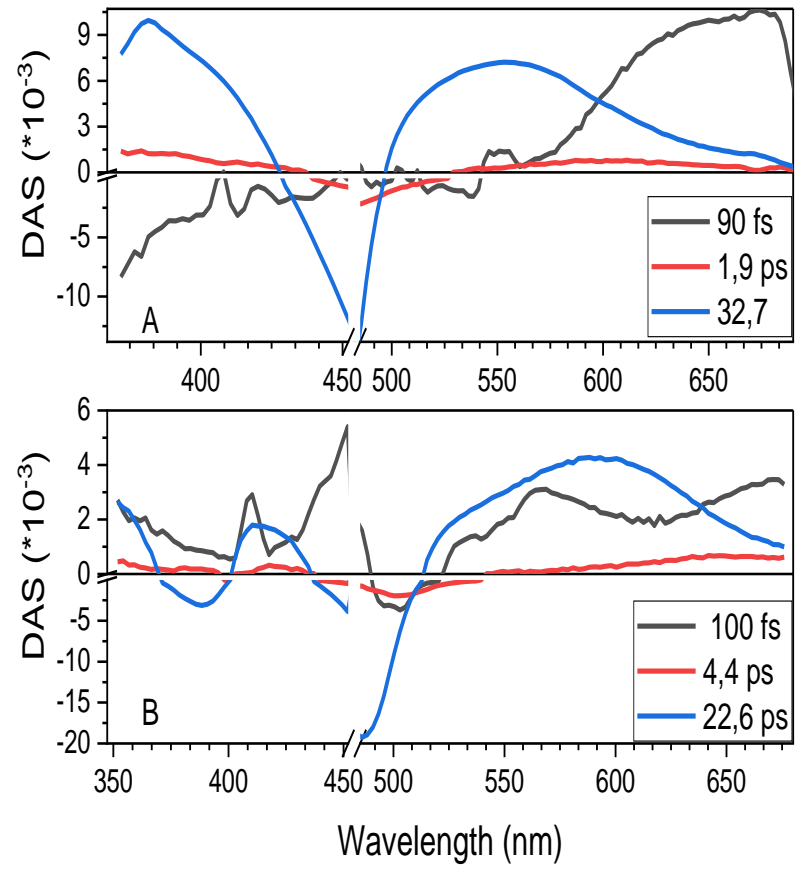

Figure 5. Decay-Associated difference Spectra of C4 (A) and C2 (B) obtained with Glotaran (see ref.22). The DAS associated with $\tau 1$ have contributions from ESA and solvent response. The amplitude and shape of the 1.9 and 4.4 ps DAS are consistent with the minor spectral evolutions on this time scale

DAS are reported in Fig 5. For C4 (panel A), the analysis converges to $\tau_{1}=90 \mathrm{fs}, \tau_{2}=2 \pm 1$ ps and $\tau_{3}=33 \pm 2$ ps whereas for C2 the fitting yields $\tau_{1}=100 \mathrm{fs}, \tau_{2}=4 \pm 1$ and $\tau_{3}=23 \pm 2 \mathrm{ps}$. In both samples, the DAS associated with $\tau_{1}$ indicate contributions both from an almost unresolved ESA relaxation and the solvent response (limited to the instrument response function), while the amplitude and shape of the 2 and 4 ps DAS are consistent with the minor spectral evolutions on this time scale.

In analogy to previous work ${ }^{14,23}$, the decay times are interpreted along the reaction scheme (1).

$$
\begin{aligned}
& { }^{1} M L C T^{+} \stackrel{<I R F}{\rightarrow}{ }^{1} M L C T \stackrel{\tau_{1}}{\rightarrow}{ }^{3} M C L T /{ }^{3} M C_{h o t} \\
& \stackrel{\tau_{2}}{\rightarrow}\left({ }^{3} M C L T /{ }^{3} M C\right)_{e q} \stackrel{\tau_{3}}{\rightarrow} S_{0}
\end{aligned}
$$

Intersystem crossing (IC) occurs on the $\approx 0.1$ ps time scale, ${ }^{7,8,9,10}$ leading to a non-emissive triplet species (no stimulated emission). It can be associated with a non-equilibrated state of MLCT, MC or mixed character (see computational part below, ${ }^{16}$ which decays within $\tau_{2}$ into the vibrationally equilibrated $\left({ }^{3} \mathrm{MLCT} /{ }^{3} \mathrm{MC}\right)_{\mathrm{eq}}$. This relaxation step is manifested by the small spectral shifts (Figure 3), which were not analysed in previous work ${ }^{23,24}$. After this relaxation step, related to structural or solvent relaxation, the population lives 32 ps for $\mathbf{C 4}$ and 22 ps for C2 (Table 2). 
Table 2: Time constants derived from the analysis of the TAS data. ${ }^{a}$

\begin{tabular}{cccc}
\hline Complex & $\tau 1$ (ps) & $\tau 2$ (ps) & $\tau$ 3 (ps) \\
\hline C1 & $0.10 \pm 0.05$ & $2-6$ & $21-25$ \\
C2 & $0.10 \pm 0.05$ & $4 \pm 1$ & $22 \pm 2$ \\
C3 & $0.10 \pm 0.05$ & $2-4$ & $11-12$ \\
C4 & $0.10 \pm 0.05$ & $1.5 \pm 0.5$ & $32 \pm 3$ \\
\hline
\end{tabular}

${ }^{\text {A }} \tau_{3}$ is the excited state lifetime, and $\tau_{1}$ and $\tau_{2}$ describe excited state relaxation according to the sequential reaction scheme (see below). In the absence of global fitting, ranges of values are indicated for $\mathbf{C 1}$ and $\mathbf{C 3}$.

Pronounced spectral shifts in compounds $\mathrm{C} 1$ and C3. Unlike the previous cases, the data for complexes $\mathbf{C 1}$ and $\mathbf{C 3}$ show pronounced dynamic shifts and narrowing of the ESA. This is highlighted in Figure 3C for $\mathbf{C 1}$, which has the same chemical structure as $\mathbf{C 2}$, except that the Hex chains are replaced by methyl groups (cf. scheme 2). C1 and $\mathbf{C 2}$ have a very similar excited state decay times $\left(\tau_{3}=21-22 \mathrm{ps}\right.$, Table $)$, but obvious differences in their ESA spectra (Figures 3B and 3C). Not only are the ESA transition energies slightly higher for C1, the spectra display pronounced dynamic shifts (no isosbestic point) and narrowing of the long-wavelength ESA band, indicative of a more significant excited state relaxation on time scales $>3 \mathrm{ps}$. This is best highlighted by the normalised data (Figure SI28). The data for $\mathbf{C 3}$ display even stronger relaxation effects, and a shorter $\tau_{3}$ lifetime (11-12 ps), as summarized in the SI.

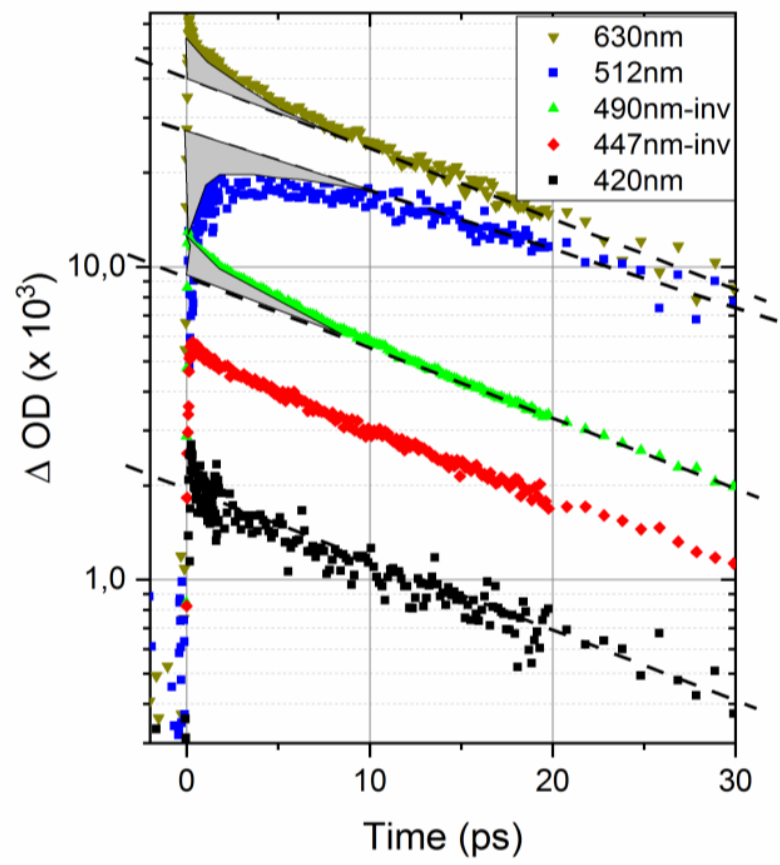

Figure 6. Kinetic traces of TAS for $\mathbf{C 1}$, on a semi-log scale. The selected wavelength cover the minor ESA band (420nm), the main GSB (447 and 490 nm) and ESA (519 and $630 \mathrm{~nm}$ ). The GSB traces are shown with inverted signs, and all traces except for $420 \mathrm{~nm}$ are shifted on the log scale by arbitrary factors. Dashed lines represent a $\approx 20$ ps decay time, as guides-to-the-eye. Shaded areas in the 490 and $519 \mathrm{~nm}$ traces highlight the deviations from single exponential decay for $\mathrm{t}<10 \mathrm{ps}$. For these wavelengths, they are due to the dynamic shift of the ESA spectrum, also seen at $630 \mathrm{~nm}$, on a 2-6 ps time scale. These effects are smaller for the minor ESA band $(<450 \mathrm{~nm})$.

For C1, the modifications of the ESA spectrum in the initial $0.1-0.2$ ps are due to ultrafast IC as above. For delays until $\approx 10$ ps, the ESA decays faster on the long wavelength side $(\geq 530$ $\mathrm{nm})$, flattens and shifts to shorter wavelengths. This gives rise to a decay at $\lambda>530 \mathrm{~nm}$, and a rise component in the $490-520$ nm range (cf. Figure 6).

The result is the progressively shifting ESA/GSB crossover point around 500-510 nm. A similar decay/blue-shift behaviour is also observed in the minor ESA band at $410-430 \mathrm{~nm}$. The ESA difference spectra steepen progressively in the 500-525 $\mathrm{nm}$ range (Figure SI28). Even though the effect may appear small, global fitting cannot be used any longer since the ESA extinction coefficient is time dependent $\varepsilon(\lambda, t)$, i.e. the oftenmade assumption of separability of wavelength and time dependencies does not hold. Note that in the present case, spectral evolution and excited state decay occur on similar time scales, particularly for $\mathbf{C 3}$ (Table ).

The results of 20 three-component fits performed for individual wavelengths are given in Figure 7. The wavelength-dependent lifetimes are highlighted in the top panel, especially for $\tau_{2}$ and $\tau_{3}$. The latter represents the excited state lifetime of $\mathbf{C 1}$, characterised by the average ground state bleach recovery of $21 \pm 1$ ps in the 430 $490 \mathrm{~nm}$ range. In the ESA region, $\tau_{3}$ is below $20 \mathrm{ps}$ for $\lambda>600 \mathrm{~nm}$ and rises slightly but significantly for shorter wavelengths, up to $24 \pm 1$ ps for $505-520 \mathrm{~nm}$. This is consistent with the different longtime slopes of the 519 and $630 \mathrm{~nm}$ traces in Figure 6.

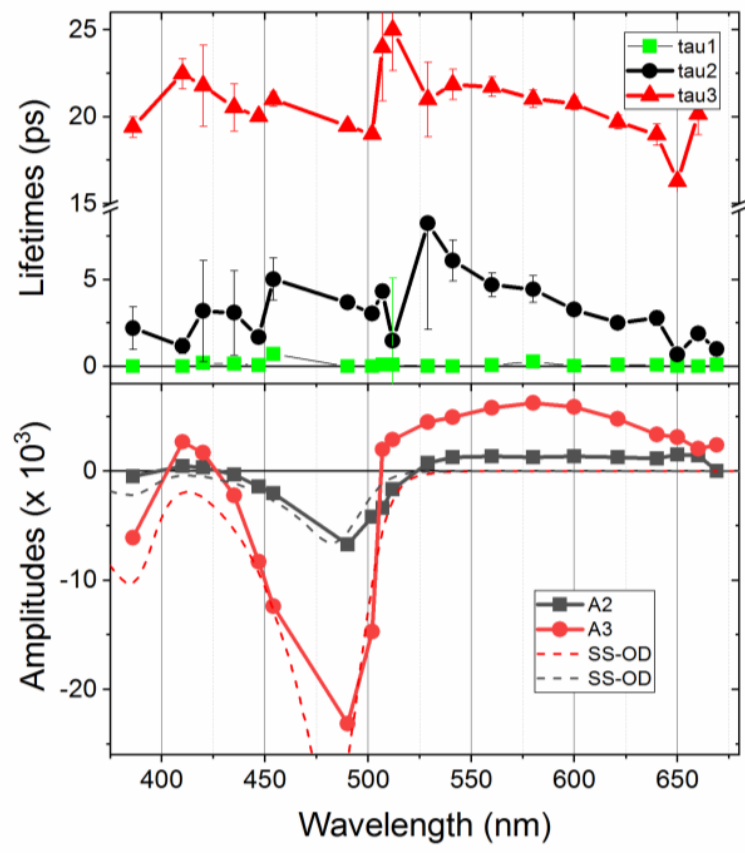

Figure 7. Results of 3-component fits for C1. Top: Lifetimes in ps; bottom: Amplitudes of the relevant components $\tau_{2}$ and $\tau_{3}$. Dashed lines show the scaled and inverted steady-state absorption spectra (SS-OD). Data in the range $460-480 \mathrm{~nm}$ are not analysed due to pump laser scatter. The decay-associated amplitudes (bottom) follow approximately the shape of GSB and ESA (Figure 3), i.e. they are mostly associated with their decay times; except for the $490-530 \mathrm{~nm}$ region, where $A_{2}$ represents an ESA rise time. 


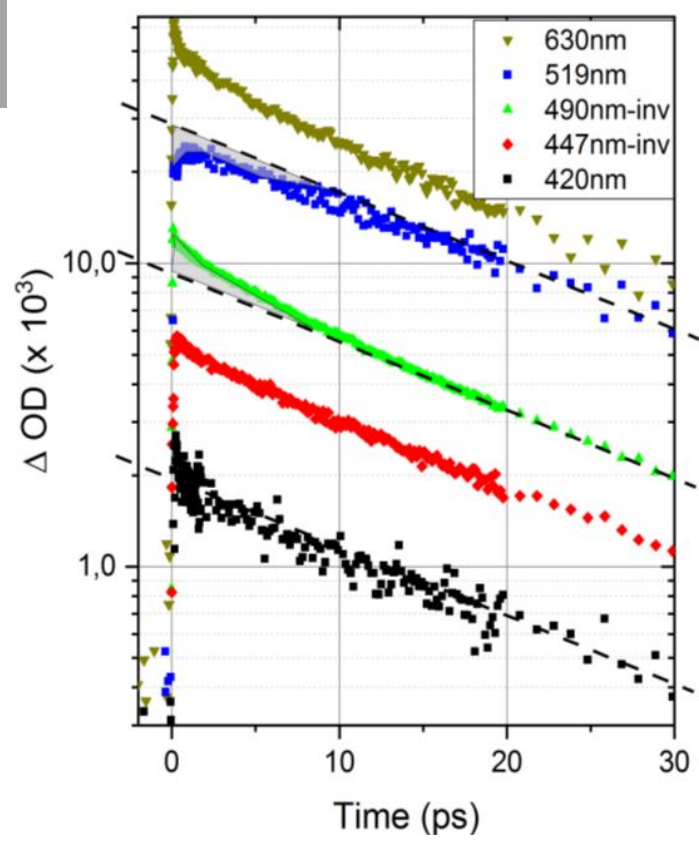

Figure 1: Kinetic traces of TAS for $\mathrm{C} 1$, on a semi-log scale. The selected wavelengths cover the minor ESA band (420nm), the main GSB (447 and 490nm) and ESA (519 and $630 \mathrm{~nm}$ ). The GSB traces are shown with inverted signs, and all traces except for $420 \mathrm{~nm}$ are shifted on the log scale by arbitrary factors. Dashed lines represent a $\approx 20$ ps decay time, as guides-to-the-eye. Shaded areas in the 490 and $519 \mathrm{~nm}$ traces highlight the deviations from single exponential decay for $\mathrm{t}<10 \mathrm{ps}$. For these wavelengths, they are due to the dynamic shift of the ESA spectrum, also seen at $630 \mathrm{~nm}$, on a 2-6 ps time scale. These effects are smaller for the minor ESA band (<

The above spectral shifts occur on the time scale of $\tau_{2}$, which follows a similar trend, i.e. increasing up to 6-8 ps in the 520$\mathrm{nm}$ region. The present situation of excited state kinetics with spectral shifts is similar to our recent report on bidentate Fe(II) complexes, and poses the question whether $\tau_{2}$ and $\tau_{3}$ represent the decays, i.e internal conversion into $\mathrm{S}_{0}$, of two separate excited state populations. For $\mathbf{C 1}$, we rather opt for a sequential scenario, as for $\mathbf{C 2}$ and $\mathbf{C 4}$, and assign the small amplitude $\tau_{2}$ to a slow excited state relaxation for two main reasons. Firstly, $\tau_{2}$ is an ESA decay time for $>530 \mathrm{~nm}$ and an ESA rise time for 500-530 nm (Figures 6 and 7). There, its amplitude is too large compared with what it would be for a GSB recovery (Figure 7, bottom panel). In the minor ESA band (400-430 nm), $\tau_{2}$ appears to be a rise time (cf. $420 \mathrm{~nm}$ trace in Erreur! Source du renvoi introuvable.), even though the fit gives a small positive amplitude due to the high noise level (see Figure SI29 for a better illustration of the rising ESA in the 490-510 $\mathrm{nm}$ and around 410-410 $\mathrm{nm}$ range). Second, comparing $\mathbf{C 1}$ and $\mathbf{C 2}$, one can envisage that the lateral hexyl/methyl chains have an influence on details of the excited state structure suggesting an effect in the structural dynamics, thus modulating the energies of ESA transitions and the value and amplitude of $\tau_{2}$ in a sequential reaction scenario. On the contrary, we do not expect the hexyl/methyl substitution to open a second faster excited state decay channel ( $\tau_{2}$ in addition to $\tau_{3}$ ), which would lead to the "parallel" excited state relaxation scenario observed for bidentate complexes. ${ }^{17}$ Therefore, $\mathbf{C 1}$ obeys the same excited state relaxation scheme (1) as $\mathbf{C 2}$ and $\mathbf{C 4}$. For C3, it is likely that $\tau_{2}$ is also associated with IC into $S_{0}$ since this component appears as a recovery time throughout the GSB band (cf. Fig. SI33). We will address the origin of the different lifetimes and the visibility of the $\tau_{2}$-related structural relaxation process in the discussion section.

\section{Computational analysis of the excited-state decay}

The photophysics of the new dyes have been analysed by means of density functional theory (DFT) and its timedependent DFT (TD-DFT) extension, given its proven good description of the electronic structure and the excited-state decay of related $\mathrm{Fe}(\mathrm{II})$ complexes. ${ }^{13}$ Figure 10 shows the calculated PESs for the lowest-lying triplet ${ }^{3} \mathrm{MLCT}$ and ${ }^{3} \mathrm{MC}$ states and the quintet ${ }^{5} \mathrm{MC}$ state for compounds $\mathbf{C 1}, \mathbf{C 3}$ and $\mathbf{C 4}$. Note that the electronic structures of $\mathbf{C 1}$ and $\mathbf{C 2}$ are very similar since they only differ in the length of the alkyl chain, therefore only the $\mathbf{C 1}$ complex has been modelled. Previous works on bidentate $\mathrm{Fe}-\mathrm{NHC}$ systems reported that $\mathrm{Fe}-\mathrm{N}$ or Fe$\mathrm{C}$ bond elongations actually drive the excited-state decay also allowing singlet-triplet crossings with the ground state. ${ }^{13,17,25}$ Thus, the curves have been built by means

of relaxed scan calculations along one of the $\mathrm{Fe}-\mathrm{N}$ bonds in order to explore the role of this coordinate in the excited-state decay in tridentate $\mathrm{Fe}(\mathrm{II})$ complexes. Note that such an approach while it has the advantage of a reduced computational cost compared to the full characterization of the PES by the calculation of minimum energy paths (MEP) only provides upper bounds to the energetic barriers encountered during the path.

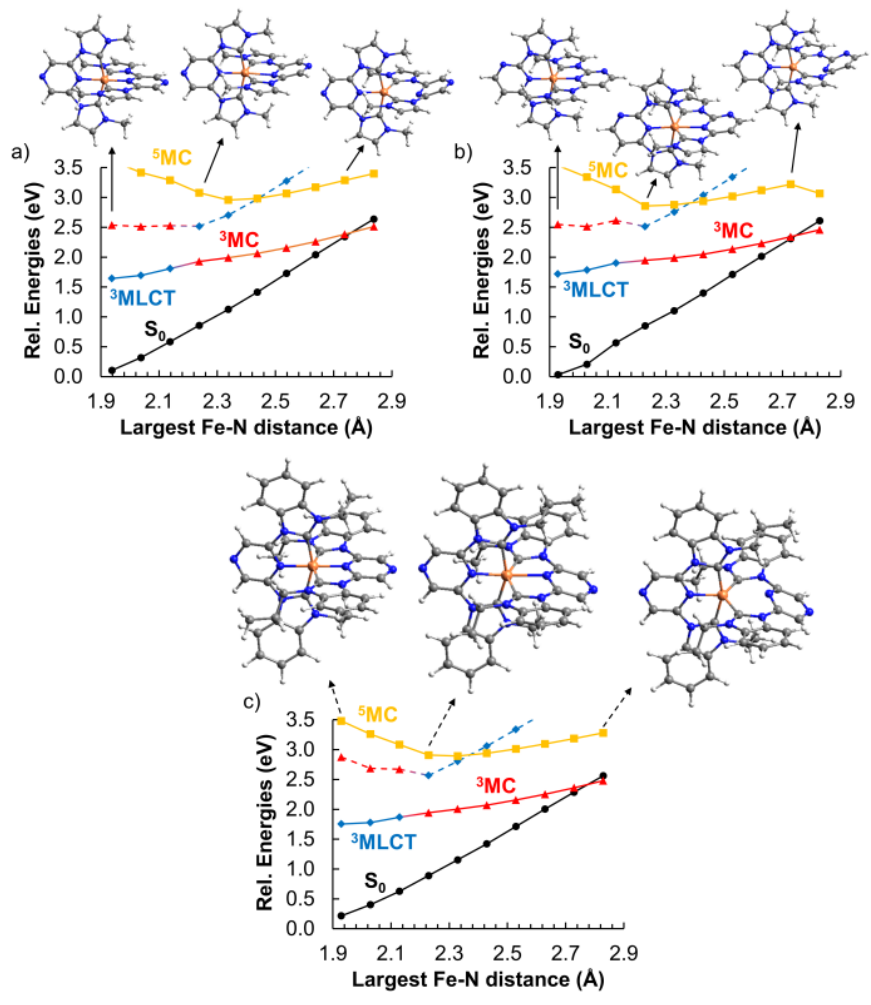

Figure 8. Fe-N relaxed scan energy profiles of a) $\mathbf{C 1}$, b) $\mathbf{C 3}$ and c) C4. For the sake of simplicity, only the lowest-lying ${ }^{3} \mathrm{MLCT},{ }^{3} \mathrm{MC}$ and ${ }^{5} \mathrm{MC}$ states are shown.

It can be readily seen that the ${ }^{3}$ MLCT minima are close to the Franck-Condon region, whereas the lowest point in the ${ }^{3} \mathrm{MC}$ curves is placed at larger Fe-N distances due to its inherent $\mathrm{Fe}$ $\mathrm{N}$ antibonding character. It shall be noted that the adiabatic energy difference between the ${ }^{3} \mathrm{MLCT}$ and ${ }^{3} \mathrm{MC}$ lowest energy 
points in the PESs, for instance of $\mathbf{C 4}(0.19 \mathrm{eV}$, see Figure $10 \mathrm{c})$, is in excellent agreement with the $0.12 \mathrm{eV}$ value reported for a related compound with similar excited-state lifetime. ${ }^{14}$

Results displayed in Figure 8 clearly indicate that the $\mathrm{Fe}-\mathrm{N}$ stretching mediates the photoresponse also in tridentate $\mathrm{Fe}$ NHC complexes, giving access to the ${ }^{3} \mathrm{MC} / \mathrm{S}_{0}$ intersystem crossings. Striking differences are however found between tridentate and bidentate complexes. ${ }^{16}$ The ps range excited-state lifetime in the former can be explained by the exploration of planar or quasi planar triplet PES regions where $S_{0}$ lies above the triplet state manifold, acting as energy traps (spin crossover). ${ }^{17}$ In tridentate compounds, the Fe-N bond stretch clearly destabilizes both $S_{0}$ and the triplet states, even though the destabilization is not uniform between the two states, hence allowing their crossing. The reason for the extended excitedstate lifetime beyond the ultrafast sub-picosecond regime can hence now be ascribed to the presence of energy barriers, found on the triplet PESs, connecting the Franck-Condon and the singlet-triplet crossing region. Note however, that the values of $\sim 0.5 \mathrm{eV}$ found for the barriers from the ${ }^{3} \mathrm{MC}$ minima to the corresponding ${ }^{3} \mathrm{MC} / \mathrm{S}_{0}$ singlet-triplet crossing points represent upper bounds and could be significantly lowered by the explicit calculations of the minimum energy paths. Furthermore, the non-adiabatic ${ }^{3} \mathrm{MC} \rightarrow \mathrm{S}_{0}$ intersystem crossings could take place at regions with triplet-singlet energy differences of $\sim 0.1-0.2 \mathrm{eV}$, and not necessarily at the crossing points shown in Figure 8 ( 2.73-2.74 $\AA$ ). As a matter of fact, we have considered $\mathbf{C 1}$ as a representative example to compute the $\mathrm{T}_{1} / \mathrm{S}_{0}$ spin-orbit coupling (SOC) along the PESs shown in Figure $8 \mathrm{a}$. The values at each $\mathrm{Fe}-\mathrm{N}$ distance are shown in Table 3, indicating a strong coupling already at $\sim 2.5-2.6 \AA$ distances, supporting intersystem crossing events at shorter iron-nitrogen elongation and hence with a lower energy cost. The adiabatic evolution of $\mathrm{T}_{1}$ from ${ }^{3} \mathrm{MLCT}$ to ${ }^{3} \mathrm{MC}$ at Fe-N distances of $c a .2 .3 \AA$ is also evidenced by the sudden increase in the SOC value of about $100 \mathrm{~cm}^{-1}$ between the 2.238 and $2.338 \AA \mathrm{Fe}-\mathrm{N}$ distances.

Table 3. $\mathrm{T}_{1} / \mathrm{S}_{0}$ SOCs for the $\mathbf{C 1}$ complex

\begin{tabular}{|c|c|c|c|c|c|c|}
\hline Fe-N (Å) & 2.138 & 2.238 & 2.338 & 2.438 & 2.538 & 2.638 \\
\hline $\operatorname{SOC}\left(\mathrm{cm}^{-1}\right)$ & 47 & 88 & 189 & 228 & 247 & 259 \\
\hline
\end{tabular}

Regarding the role of the lowest-lying quintet ${ }^{5} \mathrm{MC}$ state, the energy levels shown in Figure 8 suggest a minor participation of this state in the excited-state decay since no ${ }^{5} \mathrm{MC} / \mathrm{S}_{0}$ crossings are predicted along the explored $\mathrm{Fe}-\mathrm{N}$ distances. This consideration is coherent with the behaviour observed in bidentate Fe-NHC. ${ }^{16,17}$

Figure 9 shows the adiabatic profile of the lowest-lying 20 triplet states for the pyrazine-based complexes $\mathbf{C 1}$ and $\mathbf{C 4}$. As in the case of Fe-NHC bidentate complexes, ${ }^{16}$ only the three lowest-energy triplet states lead to singlet-triplet crossing points, whereas the higher states are extremely destabilized by the $\mathrm{Fe}-\mathrm{N}$ stretching. These results reveal the crucial role of these low-energy triplet states, since after light absorption an initial ultrafast intersystem crossing followed by vibrational cooling of the hot MLCT states is observed (see above). The upper bounds for the triplet energy barriers found in the present
TD-DFT calculations $(<0.5 \mathrm{eV}$ for the $\mathrm{Fe}-\mathrm{N}$ distances from $\sim 2.2$ to $\sim 2.5-2.7 \AA$, see Figure 8$)$ are in agreement with the experimental estimations based on the Arrhenius equation ( 0.1 $\mathrm{eV}$ ), as depicted in the discussion section.
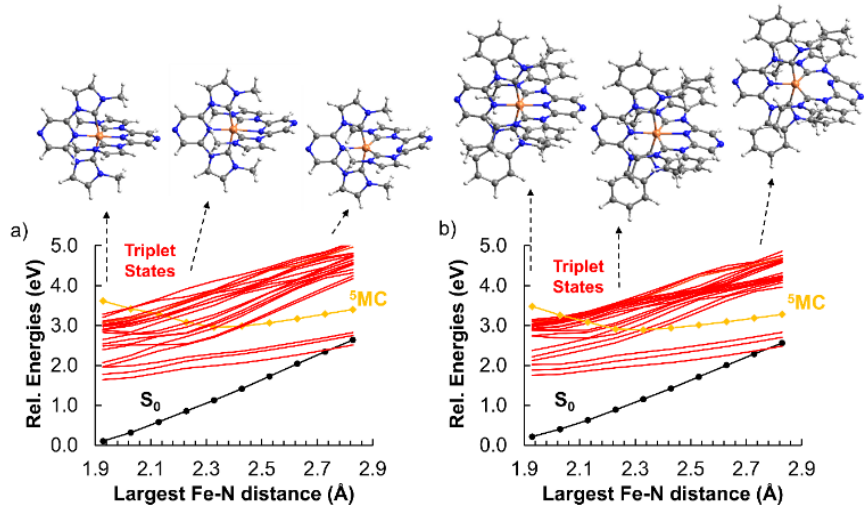

Figure 9. Fe-N relaxed scan energy profiles of a) $\mathbf{C 1}$ and $\mathbf{C 4}$. The first 20 triplet states and the lowest-lying ${ }^{5} \mathrm{MC}$ states are shown.

\section{Discussion}

The four new compounds C1-C4 investigated in this work extend our previous sets of $\mathrm{Fe}$ (II) complexes with bidentate and tridentate ligands bearing respectively three and four carbene bonds. In all cases, the ligand field enhancement is large enough to prevent excited state relaxation into the ${ }^{5} \mathrm{~T}_{2}$ high spin manifold. ${ }^{13}$ According to reaction scheme (1), ultrafast spectroscopy monitors the sub-100 fs ${ }^{1}$ MLCT $\rightarrow{ }^{3}$ MLCT intersystem crossing, and, most importantly, the effect of the ligand's nature on the ${ }^{3} \mathrm{MLCT} /{ }^{3} \mathrm{MC}$ lifetime. The present combined experimental and theoretical study rationalises the combined effect of the electronic deficiency of the pyrazine and benzimidazolylidene (BIm) moieties in lowering the ${ }^{3}$ MLCT energy, in analogy to the strategy described previously. ${ }^{14}$

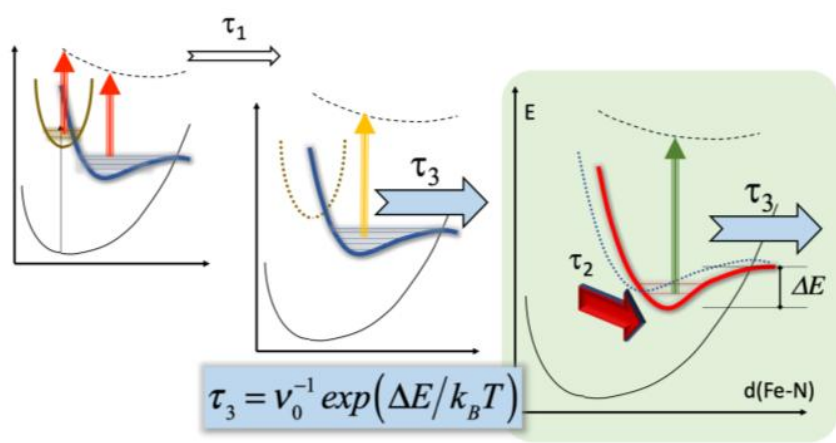

Figure 10. Sketch of the ultrafast excited state relaxation processes, along the PES of ${ }^{1} \mathrm{MLCT}$ (brown) and the triplet manifold (blue/red). In phase 1, vibrational relaxation brings the population into the ${ }^{3} \mathrm{MLCT}$ state $\left(\tau_{1}\right)$. Structural and/or dielectric relaxation (red arrow) acts during phase $2, \tau_{2}$, and stabilises the populations in the red PES, leading to red-shift of ESA. Population decay into $S_{0}$ takes place during both phases at 
the cost of a small activation barrier $\Delta \mathrm{E}$, situated along the Fe-N coordinate. Red yellow and green arrows indicate the dynamically shifting ESA transitions.

We find that BIm is again most effective in this respect allowing to achieve, for $\mathbf{C 4}$, an excited state lifetime of $\tau_{3}=$ $32 \pm 2$ ps, meaning a $\approx 30 \%$ increase with respect to $\mathbf{C 1}$ and $\mathbf{C 2}$. As indicated in Figures 8 and 9, the ISC and relaxation into the singlet ground state involves $\mathrm{Fe}-\mathrm{N}$ stretching and thus a MLCT $\rightarrow$ MC conversion, but at the cost of an activation energy $<0.5 \mathrm{eV}$ according to the PESs. Alternatively, if we express $\tau_{3}$ by the Arrhenius law, $\tau_{3}=v_{0}^{-1} \exp \left(\Delta E / k_{B} T\right)$, and supposing $\mathrm{v}_{0}=3-4 \mathrm{ps}^{-1}$ for the excited state $\mathrm{Fe}-\mathrm{N}$ stretch frequency, one may estimate the excited state barrier $\Delta E$ to be in the range of 3.5 to $5.0 \mathrm{k}_{\mathrm{B}} \mathrm{T}$, meaning 90 to $130 \mathrm{meV}$ (Figure 10), in agreement with the TD-DFT computations. Slight modulations of the excited state energy landscape lead to the variation of a factor of $\approx 2.7$ in the excited-state lifetime (12 to $32 \mathrm{ps})$.

A tentative explanation for the different excited-state lifetimes measured for the C1-C4 series can be formulated on the basis of possible out-of-plane (OOP) distortions in the ${ }^{3} \mathrm{MLCT}$ state located on the electron accepting nitrogen of the diazine ring, not considered in the present computations. In the ${ }^{3}$ MLCT state, the extra charge on the ring breaks the aromaticity, since the number of $\pi$ electrons is now $4 n+3$, which can lead to an OOP deformation, located on the electron accepting nitrogen. The higher the charge density over the Fe-coordinating nitrogen, the larger the out-of-plane amplitude and thus the driving force for increasing the Fe-N distance. Comparing pyrazine-based complexes (C1 and $\mathbf{C 2}$ ) and pyrimidine-based one (C3), that will have an asymmetric excited state charge distribution, one may expect, for the latter, a higher electron density on the Fe-coordinating nitrogen and thus a lower $\Delta \mathrm{E}$, consistent with the shorter excited-state lifetime observed. C4 on the other hand, will have a smaller excess electron density on the pyrazine ring since the BIm moieties have a larger electron accepting character. ${ }^{14}$ The OOP driving force is thus minimal for $\mathbf{C 4}$, consistent with its longer excited-state lifetime. Further calculations are required to validate these hypotheses.

In addition to the excited-state lifetime, we report above a hitherto overlooked excited state relaxation process acting during $\tau_{2}$. The effect manifested by the ESA blue-shift is most pronounced in $\mathbf{C 1}$ and $\mathbf{C 3}$, while virtually absent in $\mathbf{C 2}$ and $\mathbf{C 4}$. The latter are bearing lateral hexyl chains instead of methyl groups in the former. The long hexyl chains can interact with the diazine rings of the other tridentate ligand. We argue that this interaction hinders the above out-of-plane (OOP) motion, and thus the additional structural relaxation. Consequently, and since OOP deformation increases the $\mathrm{Fe}-\mathrm{N}$ and thus helps reaching the $T_{1} / S_{0}$ crossing points (see Figure 10), the general trend of "more pronounced spectral relaxation effects go along with shorter excited state lifetimes" (C1 and C3) is expected. An alternative explanation for the $\tau_{2}$ process would refer to dynamic solvation, i.e. re-orientation of the polar acetonitrile solvent molecules as a response to the electron density increase on the ligands in the ${ }^{3}$ MLCT states. ${ }^{26}$ Here again, the hexyl chains would decrease the effect due to a reduced ligandsolvent interaction.

\section{Conclusions}

The present combined experimental and computational study investigates the effect of replacing pyridine by diazines in tridentate $\mathrm{C}^{\wedge} \mathrm{N}^{\wedge} \mathrm{C}$ heterocyclic ligands in $\mathrm{Fe}$ (II) complexes. It reveals several factors, which are beneficial in stabilising the excited-state, leading to an improved > $30 \mathrm{ps}$ excited-state lifetime for this class of four-carbene coordinating ligands. These ligands, as much as carboxylic acid groups used in our previous studues, ${ }^{20}$ lower the MLCT energies in the FranckCondon region, in addition to the BIm moieties. In addition, the present study confirms, from a computational viewpoint, the role of the $\mathrm{Fe}-\mathrm{N}$ distance increase required for the excited state decay. Experiments indicated that an energy barrier must be overcome to reach the corresponding ${ }^{3} \mathrm{MC} / \mathrm{S}_{0}$ crossing points, which mediate the decay to the ground state. The possible role of the electronic charge distribution over the $\mathrm{C}^{\wedge} \mathrm{N}^{\wedge} \mathrm{C}$ ligands and the propensity of the diazine ring to undergo out-of-plane motion is also discussed. The present work provides useful synthetic tools to design Fe(II) complexes with long-lived excited-state lifetimes, and represents a step further in the comprehension of the intricate photo processes taking place in first-row transition metal complexes.

\section{Experimental and computational details}

\section{Synthesis}

Solvents and commercially available reagents were used as received. Thin layer chromatography (TLC) was performed by using silica gel 60 F-254 (Merck) plates and visualized under UV light. Chromatographic purification was performed by using silica gel $60(0.063-0.2 \mathrm{~mm} / 70-230 \mathrm{mesh}) .{ }^{1} \mathrm{H}(400$ $\mathrm{MHz})$ and ${ }^{13} \mathrm{C}$ NMR (100 MHz) spectra were taken on a DRX400 Bruker spectrometer at ambient temperature. The chemical shifts $(\delta)$, were calibrated by using either tetramethylsilane (TMS) or signals from the residual protons of the deuterated solvents and are reported in parts per million (ppm) from low to high field. High-resolution mass spectrometry (HRMS) data was obtained by using Bruker micrOTOF-Q spectrometer. UV-vis spectra were recorded in a $1 \mathrm{~cm}$ path length quartz cell on a LAMBDA 1050 (Perkin Elmer), spectrophotometer. Cyclic voltammetry was performed on a Radiometer PST006 potentiostat using a conventional three-electrode cell. The saturated calomel electrode (SCE) was separated from the test compartment using a bridge tube. The solutions of studied complexes $(0.2 \mathrm{mM})$ were purged with argon before each measurement. The test solution was acetonitrile containing $0.1 \quad \mathrm{M} \quad \mathrm{Bu}_{4} \mathrm{NPF}_{6}$ as supporting electrolyte. The working electrode was a vitreous carbon rod $(1 \mathrm{~cm} 2)$ wire and the counter-electrode was a $1 \mathrm{~cm}^{2} \mathrm{Pt}$ disc. After the measurement, ferrocene was added as the internal reference for calibration. All potentials were quoted versus SCE. In these conditions the redox potential of the couple 
$\mathrm{Fc}+/ \mathrm{Fc}$ was found at $0.39 \mathrm{~V}$. In all the experiments the scan rate was $100 \mathrm{mV} / \mathrm{s}$.

\section{Synthesis of ligands}

$\mathbf{L 1}^{27}$ : To a solution of 2,6-dichloropyrazine (300 mg, 2.01 $\mathrm{mmol}$ ) in $40 \mathrm{~mL}$ of dioxane, was added an excess of 1-methyl1H-imidazole $(0.64 \mathrm{~mL}, 8.06 \mathrm{mmol})$ and the mixture was refluxed overnight. After cooling at room temperature, a saturated solution of $\mathrm{KPF}_{6}$ was added $(20 \mathrm{~mL})$, the precipitate was washed with distilled water and dried under vacuum affording L1 (750 mg, 70\%). ${ }^{1} \mathrm{H}$ NMR (400 MHz, $\left.\mathrm{CD}_{3} \mathrm{CN}\right): \delta$ $9.44(\mathrm{~s}, 2 \mathrm{H}), 9.22(\mathrm{~s}, 2 \mathrm{H}), 8.22(\mathrm{~s}, 2 \mathrm{H}), 7.67(\mathrm{~s}, 2 \mathrm{H}), 4.03(\mathrm{~s}$, $6 \mathrm{H}) .{ }^{13} \mathrm{C}$ NMR $\left(101 \mathrm{MHz}, \mathrm{CD}_{3} \mathrm{CN}\right): \delta$ 141.6, 137.2, 136.3, 126.2, 120.1, 37.5. HRMS (ESI) calcd for $\mathrm{C}_{12} \mathrm{H}_{14} \mathrm{~N}_{6} \mathrm{P}_{2} \mathrm{~F}_{12} \mathrm{~m} / \mathrm{z}=$ $121.0634\left[\mathrm{M}-2 \mathrm{PF}_{6}\right]^{2+}$. Found: 121.0631.

L2: To a solution of 2,6-dichloropyrazine (180 mg, $1.21 \mathrm{mmol}$ ) in $20 \mathrm{~mL}$ of dioxane, was added an excess of 1-hexyl-1Himidazole (736 mg, $4.83 \mathrm{mmol}$ ) and the mixture was refluxed overnight. After cooling at room temperature, a saturated solution of $\mathrm{KPF}_{6}$ was added $(10 \mathrm{ml})$, the precipitate was washed with distilled water and dried under vacuum affording L2 (600 $\mathrm{mg}, 74 \%):{ }^{1} \mathrm{H}$ NMR (400 MHz, $\left.\mathrm{CD}_{3} \mathrm{CN}\right) \delta 9.48(\mathrm{~s}, 2 \mathrm{H}), 9.23(\mathrm{~s}$, $2 \mathrm{H}), 8.26(\mathrm{t}, \mathrm{J}=1.9 \mathrm{~Hz}, 2 \mathrm{H}), 7.72(\mathrm{t}, \mathrm{J}=1.9 \mathrm{~Hz}, 2 \mathrm{H}), 4.33(\mathrm{t}, \mathrm{J}$ $=7.4 \mathrm{~Hz}, 4 \mathrm{H}), 2.02-1.95(\mathrm{~m}, 4 \mathrm{H}), 1.45-1.29(\mathrm{~m}, 12 \mathrm{H}), 0.91$ $(\mathrm{t}, \mathrm{J}=7.1 \mathrm{~Hz}, 6 \mathrm{H}) .{ }^{13} \mathrm{C} \mathrm{NMR}\left(101 \mathrm{MHz}, \mathrm{CD}_{3} \mathrm{CN}\right) \delta 141.6$, 137.1, 135.6, 124.9, 120.3, 51.4, 31.3, 29.8, 25.9, 22.7, 13.8. HRMS (ESI) calcd for $\mathrm{C}_{22} \mathrm{H}_{34} \mathrm{~N}_{6} \mathrm{PF}_{6} \mathrm{~m} / \mathrm{z}=381.2761\left[\mathrm{M}-\mathrm{PF}_{6}\right]$ ${ }^{+}$. Found: 381.2765 .

L3: To a solution of 2,4-dichloropyrimidine (250 mg, 1.68 $\mathrm{mmol})$ in $30 \mathrm{~mL}$ of dioxane, was added an excess of 1-methyl1H-imidazole (530 $\mathrm{mg}, 6.71 \mathrm{mmol}$ ) and the mixture was refluxed overnight. After cooling at room temperature, $40 \mathrm{~mL}$ of diethyl ether was added and the precipitate was filtered and dried under vacuum affording $\mathbf{L 3}$ (405 mg, 77\%): ${ }^{1} \mathrm{H}$ NMR $\left(400 \mathrm{MHz}, \mathrm{CD}_{3} \mathrm{CN}\right) \delta 9.58(\mathrm{~s}, 2 \mathrm{H}), 9.18(\mathrm{~d}, \mathrm{~J}=5.6 \mathrm{~Hz}, 1 \mathrm{H})$, $8.30(\mathrm{~d}, \mathrm{~J}=17.1 \mathrm{~Hz}, 2 \mathrm{H}), 7.91(\mathrm{~d}, \mathrm{~J}=5.5 \mathrm{~Hz}, 1 \mathrm{H}), 7.64(\mathrm{~d}, \mathrm{~J}=$ $8.7 \mathrm{~Hz}, 2 \mathrm{H}), 4.03(\mathrm{~s}, 6 \mathrm{H}) .{ }^{13} \mathrm{C} \mathrm{NMR}\left(101 \mathrm{MHz}, \mathrm{D}_{2} \mathrm{O}\right) \delta 163.9$, $154.8,152.3,125.6,125.0,119.4,110.6,36.7$. HRMS (ESI) calcd for $\mathrm{C}_{12} \mathrm{H}_{14} \mathrm{~N}_{6} \mathrm{Cl}_{2} \mathrm{~m} / \mathrm{z}=121.0634[\mathrm{M}-2 \mathrm{Cl}]^{2+}$. Found: 121.0632 .

$\mathbf{L 4}^{27}$ : A solution of Benzimidazole (642 $\mathrm{mg}, 5.44 \mathrm{mmol}$ ) in anhydrous DMF (3mL) was added dropwise to the suspension of $\mathrm{NaH} 95 \%(137 \mathrm{mg})$ in anhydrous DMF $(3 \mathrm{~mL})$ over a period of $15 \mathrm{~min}$ at room temperature under inert atmosphere. Then a solution of 2,6-dichloropyrazine $(300 \mathrm{mg}, 2.01 \mathrm{mmol})$ in anhydrous DMF $(3 \mathrm{~mL})$ was added, and the mixture was refluxed overnight. The reaction mass $\mathrm{pH}$ was then adjusted to $\mathrm{pH} 6.2$ by adding $20 \mathrm{~mL}$ of distilled water. The precipitate formed was subsequently filtered and washed with water and dried under vacuum affording 2,6-bis(1H-benzo[d]imidazol-1yl)pyrazine (BisBIm-Pz) (533 mg, 84\%) ${ }^{1} \mathrm{H}$ NMR (400 MHz, DMSO-d6) $\delta 9.32(\mathrm{~s}, 2 \mathrm{H}), 9.19(\mathrm{~s}, 2 \mathrm{H}), 8.29(\mathrm{dd}, \mathrm{J}=6.2,2.6$ $\mathrm{Hz}, 2 \mathrm{H}), 7.86(\mathrm{dd}, \mathrm{J}=6.2,2.8 \mathrm{~Hz}, 2 \mathrm{H}), 7.49-7.34(\mathrm{~m}, 4 \mathrm{H})$. HRMS (ESI) calcd for $\mathrm{C}_{20} \mathrm{H}_{17} \mathrm{~N}_{6} \mathrm{~m} / \mathrm{z}=313.1196[\mathrm{M}+\mathrm{H}]{ }^{+}$. Found: 341.1509. To a solution of BisBIm-Pz (150 mg, 0.48 mmol) in $2 \mathrm{~mL}$ DMF was added $0.18 \mathrm{~mL}$ of methyl iodide $(1.93 \mathrm{mmol})$ and the mixture was refluxed overnight. After cooling at room temperature, a saturated solution of $\mathrm{KPF}_{6}$ was added $(10 \mathrm{ml})$, the precipitate was washed with distilled water and dried under vacuum affording $\mathbf{L 4}(255 \mathrm{mg}, 84 \%){ }^{1} \mathrm{H}$ NMR (400 MHz, DMSO-d6) $\delta 10.77(\mathrm{~s}, 2 \mathrm{H}), 9.61(\mathrm{~s}, 2 \mathrm{H}), 8.45$ (d, J $=8.2 \mathrm{~Hz}, 2 \mathrm{H}), 8.24(\mathrm{~d}, \mathrm{~J}=8.1 \mathrm{~Hz}, 2 \mathrm{H}), 7.83(\mathrm{dt}, \mathrm{J}=24.0,7.7$ $\mathrm{Hz}, 4 \mathrm{H}), 4.31(\mathrm{~s}, 6 \mathrm{H}) \cdot{ }^{13} \mathrm{C}$ NMR (101 MHz, DMSO-d6) $\delta$ 144.0, 142.6, 139.1, 132.6, 129.7, 128.7, 128.1, 115.8, 114.9, 34.7. HRMS (ESI) calcd for $\mathrm{C}_{12} \mathrm{H}_{14} \mathrm{~N}_{6} \mathrm{I} \mathrm{m} / \mathrm{z}=341.1507$ [M - I] + . Found: 341.1509 .

L5. Br : To a solution of BisBIm-Pz (150 mg, $0.78 \mathrm{mmol})$ in $3 \mathrm{~mL}$ DMF was added $0.46 \mathrm{~mL} 1$-bromohexane $(1.93 \mathrm{mmol})$ and the mixture was refluxed overnight. After cooling at room temperature, $30 \mathrm{~mL}$ diethyl ether was added and the precipitate was filtered and dried under vacuum affording $\mathbf{L 5} . \mathrm{Br}(225 \mathrm{mg}$, $73 \%){ }^{1} \mathrm{H}$ NMR (400 MHz, DMSO-d6) $\delta 10.80$ (s, 2H), 9.62 (s, $2 \mathrm{H}), 8.45(\mathrm{~d}, \mathrm{~J}=8.3 \mathrm{~Hz}, 2 \mathrm{H}), 8.32(\mathrm{~d}, \mathrm{~J}=8.2 \mathrm{~Hz}, 2 \mathrm{H}), 7.81(\mathrm{dt}$, $\mathrm{J}=15.3,7.4 \mathrm{~Hz}, 4 \mathrm{H}), 4.70(\mathrm{t}, \mathrm{J}=7.3 \mathrm{~Hz}, 4 \mathrm{H}), 2.14-1.98(\mathrm{~m}$, $4 \mathrm{H}), 1.53-1.43(\mathrm{~m}, 4 \mathrm{H}), 1.41-1.26(\mathrm{~m}, 8 \mathrm{H}), 0.89(\mathrm{t}, \mathrm{J}=7.0$ $\mathrm{Hz}, 6 \mathrm{H}) .{ }^{13} \mathrm{C}$ NMR (101 MHz, DMSO-d6) $\delta 142.9,142.0$, $138.6,131.4,129.4,128.1,127.6,115.5,114.4,47.5,30.6$, 28.3, 25.3, 21.8, 13.8. HRMS (ESI) calcd for $\mathrm{C}_{30} \mathrm{H}_{37} \mathrm{~N}_{6} \mathrm{Br}_{2} \mathrm{~m} / \mathrm{z}$ $=481.3074[\mathrm{M}-2 \mathrm{Br}]^{+}$. Found: 481.3044

\section{Synthesis of complexes}

General procedure of the synthesis of $\mathbf{C 1}, \mathbf{C 2}$ and $\mathbf{C 3}$ : To a solution of the appropriate ligand $\mathrm{L}(1 \mathrm{eq})$ in $2 \mathrm{~mL}$ of anhydrous DMF were added simultaneously a solution of KHMDS (4 eq) in $2 \mathrm{~mL}$ anhydrous DMF and a solution of $\mathrm{FeBr}_{2}(0.5 \mathrm{eq})$ in anhydrous $1 \mathrm{~mL} \mathrm{DMF}$, the resulting dark red mixture was stirred at room temperature for $10 \mathrm{~min}$. A saturated solution of $\mathrm{KPF}_{6}$ was added $(10 \mathrm{ml})$, and the precipitate was collected by filtration. The solid was purified by column chromatography eluting with an acetone $/ \mathrm{H}_{2} \mathrm{O} / \mathrm{KNO}_{3}$ (sat) $=10$ : 3: 1 mixture. The yellow fraction was collected and after the evaporation of acetone, the left solution was treated with a saturated solution of $\mathrm{KPF}_{6}$. Affording the precipitation of the complex, it was then filtered, washed with distilled water and dried under vacuum.

C1: The general procedure starting from L1 (148 mg, $0.28 \mathrm{mmol})$, KHMDS (222 $\mathrm{mg}, 1.11 \mathrm{mmol})$ and $\mathrm{FeBr}_{2}(30 \mathrm{mg}$, $0.14 \mathrm{mmol})$ gave $\mathbf{C 1}\left(23 \mathrm{mg}, 20 \%\right.$ yield). ${ }^{1} \mathrm{H} \mathrm{NMR}(400 \mathrm{MHz}$, $\left.\mathrm{CD}_{3} \mathrm{CN}\right) \delta 9.04(\mathrm{~s}, 4 \mathrm{H}), 8.13(\mathrm{~d}, \mathrm{~J}=2.2 \mathrm{~Hz}, 4 \mathrm{H}), 7.04(\mathrm{~d}, \mathrm{~J}=$ $2.2 \mathrm{~Hz}, 4 \mathrm{H}), 2.51(\mathrm{~s}, 12 \mathrm{H}) .{ }^{13} \mathrm{C}$ NMR $\left(101 \mathrm{MHz}, \mathrm{CD}_{3} \mathrm{CN}\right) \delta$ 198.0, 150.9, 128.0, 126.6, 117.5, 35.2. HRMS (ESI) calcd for $\mathrm{C}_{24} \mathrm{H}_{24} \mathrm{FeN}_{12} \mathrm{P}_{2} \mathrm{~F}_{12} \mathrm{~m} / \mathrm{z}=268.0793\left[\mathrm{M}-2 \mathrm{PF}_{6}\right]^{2+}$. Found: 268.0816 C2: The general procedure starting from L2 $(187 \mathrm{mg}, 0.28$ mmol), KHMDS (222mg, $1.11 \mathrm{mmol}$ ) and $\mathrm{FeBr}_{2}$ (46 mg, 0.14 mmol) gave $\mathrm{C} 2\left(23 \mathrm{mg}, 30 \%\right.$ yield). ${ }^{1} \mathrm{H}$ NMR (400 MHz, $\left.\mathrm{CD}_{3} \mathrm{CN}\right): \delta 9.12(\mathrm{~s}, 4 \mathrm{H}), 8.23(\mathrm{~d}, \mathrm{~J}=2.2 \mathrm{~Hz}, 4 \mathrm{H}), 7.18(\mathrm{~d}$, $\mathrm{J}=2.3 \mathrm{~Hz}, 4 \mathrm{H}), 2.60(\mathrm{t}, \mathrm{J}=2.2 \mathrm{~Hz} 8 \mathrm{H}), 1.17-1.09(\mathrm{~m}, 8 \mathrm{H}), 1.04$ $-0.95(\mathrm{~m}, 8 \mathrm{H}), 0.82(\mathrm{t}, \mathrm{J}=7.3 \mathrm{~Hz}, 20 \mathrm{H}), 0.66-0.56(\mathrm{~m}$, $8 \mathrm{H}) .{ }^{13} \mathrm{C}$ NMR $\left(101 \mathrm{MHz}, \mathrm{CD}_{3} \mathrm{CN}\right) \delta 196.6,150.9,127.1$, 126.7, 49.7, 31.6, 31.0, 26.2, 22.7, 13.8. HRMS (ESI) calcd for $\mathrm{C}_{44} \mathrm{H}_{64} \mathrm{~N}_{12} \mathrm{P}_{2} \mathrm{~F}_{12} \mathrm{~m} / \mathrm{z}=408.2358\left[\mathrm{M}-2 \mathrm{PF}_{6}\right]^{2+}$. Found: 408.2406 . C3: The general procedure starting from $\mathbf{L 3}(101 \mathrm{mg}, 0.32$ mmol), KHMDS (238 mg, $1.30 \mathrm{mmol})$ and $\mathrm{FeBr}_{2}(35 \mathrm{mg}, 0.16$ 
mmol) gave C3 (20 mg, 15\% yield). ${ }^{1} \mathrm{H}$ NMR (400 MHz, $\left.\mathrm{CD}_{3} \mathrm{CN}\right): \delta 8.91(\mathrm{~d}, \mathrm{~J}=5.6 \mathrm{~Hz}, 2 \mathrm{H}), 8.08(\mathrm{dd}, \mathrm{J}=15.1,2.1,4 \mathrm{H})$, $7.79(\mathrm{~d}, \mathrm{~J}=5.7 \mathrm{~Hz}, 2 \mathrm{H}), 7.06(\mathrm{dd}, \mathrm{J}=9.7,2.0 \mathrm{~Hz}, 4 \mathrm{H}), 2.56(\mathrm{~d}$, $\mathrm{J}=5.5 \mathrm{~Hz}, 12 \mathrm{H}) .{ }^{13} \mathrm{C}$ NMR $\left(101 \mathrm{MHz}, \mathrm{CD}_{3} \mathrm{CN}\right) \delta 202.1,199.4$, $161.2,159.4,157.2,128.4,127.8,116.8,102.9,35.5,35.51$. HRMS (ESI) calcd for $\mathrm{C}_{24} \mathrm{H}_{24} \mathrm{FeN}_{12} \mathrm{P}_{2} \mathrm{~F}_{12} \mathrm{~m} / \mathrm{z}=268.0793[\mathrm{M}$ $\left.2 \mathrm{PF}_{6}\right]^{2+}$. Found: 268.0811 .

C4: A Schlenk tube was loaded with L5.Br (149 mg, 0.23 $\mathrm{mmol}$ ) then $5 \mathrm{~mL}$ of dry THF was added under inert atmosphere. The reaction mixture was cooled to $-10{ }^{\circ} \mathrm{C}$ and LiHMDS (0.46 mL, $0.46 \mathrm{mmol}, 1 \mathrm{M}$ in THF) was added dropwise over $30 \mathrm{~min}$. The cooling bath was removed, and the temperature allowed to raise slowly up to $20^{\circ} \mathrm{C}$. The reaction mixture was then stirred for $1 \mathrm{~h}$. A solution of anhydrous $\mathrm{FeBr}_{2}$ $(25 \mathrm{mg}, 0.11 \mathrm{mmol})$ in dry THF ( $3 \mathrm{~mL})$ was finally added via syringe to the Schlenk tube. The reaction mixture was stirred at room temperature for $24 \mathrm{~h}$ after which, the solvent was removed under reduced pressure. $3 \mathrm{~mL}$ of distilled water was added followed by $10 \mathrm{~mL}$ of a saturated solution of $\mathrm{KPF}_{6}$ and the precipitate was collected by filtration. The solid was purified by column chromatography eluting with a acetone $/ \mathrm{H}_{2} \mathrm{O} / \mathrm{KNO}_{3}$ (sat.) = 10: 3: 1 mixture. The yellow fraction was collected and after the evaporation of acetone, the residue was treated with a saturated solution of $\mathrm{KPF}_{6}$ leading to precipitation of the complex that was then filtered, washed with distilled water and dried under vacuum giving C4 (20 mg, 13\% yield). ${ }^{1} \mathrm{H}$ NMR (400 MHz, DMSO-d6): $\delta 9.51$ (s, 4H), 8.13 (d, $\mathrm{J}=8.4 \mathrm{~Hz}, 4 \mathrm{H}), 7.98(\mathrm{~d}, \mathrm{~J}=8.3 \mathrm{~Hz}, 4 \mathrm{H}), 7.48(\mathrm{dt}, \mathrm{J}=15.4,7.5 \mathrm{~Hz}$ $8 \mathrm{H}), 2.80(\mathrm{t}, \mathrm{J}=8.1,8 \mathrm{H}) .1 .21-1.10(\mathrm{~m}, 8 \mathrm{H}), 1.06-0.97(\mathrm{~m}$, $8 \mathrm{H}), 0.98-0.82(\mathrm{~m}, 20 \mathrm{H}), 0.64(\mathrm{t}, \mathrm{J}=7.1,8 \mathrm{H}) .{ }^{13} \mathrm{C}$ NMR $(101$ MHz, DMSO-d6) $\delta 193.1,140.5,137.1,129.9,127.9,126.6$, 126.0, 113.9, 112.8, 49.8, 31.7, 31.1, 26.3, 22.8, 13.9. HRMS (ESI) calcd for $\mathrm{C}_{60} \mathrm{H}_{72} \mathrm{FeN}_{12} \mathrm{P}_{2} \mathrm{~F}_{12} \mathrm{~m} / \mathrm{z}=508.2671\left[\mathrm{M}-2 \mathrm{PF}_{6}\right]^{2+}$. Found: 508.2656.

\section{Computational details}

The ground-state equilibrium structures of all the complexes have been optimized using the standard DFT/B3LYP functional in combination with the $6-31+\mathrm{G}(\mathrm{d}, \mathrm{p})$, as implemented in the GAUSSIAN 09 (D.01 revision) software package. ${ }^{28}$ This computational protocol has repeatedly proven its ability to describe the Franck-Condon geometry of many $\mathrm{Fe}(\mathrm{II})$ complexes. ${ }^{29-31}$ Note that the hexyl groups of $\mathrm{C} 4$ have been substituted by ethyl groups in order to make the computations more affordable. The excited states at the Franck-Condon area have been computed by means of the TD-DFT method using the Tamm-Dancoff approximation, ${ }^{32}$ in particular making use of the exchange correlation functional HCTH407 (hereafter, TD-HCTH), ${ }^{33}$ according to previous studies on similar Fe-NHC systems as documented by our research group. ${ }^{13,14,16,20,34}$ The theoretical spectra reported in the ESI have been obtained by sampling the nuclear density of the Franck-Condon region through a semiclassical Wigner distribution of 20 structures, and convoluting the excitation energies with Gaussian functions with a full-width at half-length (FWHL) of $0.3 \mathrm{eV}$. The first 40 singlet-singlet vertical absorptions have been computed for each geometry, making use of the larger 6-311G(d,p) basis set.
The nature of the excitations have been determined by computing the NTOs, ${ }^{35,36}$ via post-processing of their density matrices obtained with the TD-HCTH method, using the NANCY_EX code. ${ }^{36,37}$ For the readers' convenience, we remind that NTOs may be considered as the best orbitals to describe a given electronic transition, and in contrast to the Kohn-Sham representation, often one or two couples of occupied/virtual orbitals are enough to fully describe the electronic density rearrangement in the excited state.

Whereas all triplet energies reported in the present work have been obtained with the TD-HCTH method and the 6-311G(d,p) basis set, different optimization techniques and basis sets have been employed to compute the different geometries that compose the PESs. The ${ }^{3}$ MLCT equilibrium geometries have been obtained by means of TD-HCTH/6-31+G(d,p) optimizations using standard minimization algorithms. Starting from the latter structures, the Fe- $\mathrm{N}$ connectivity with the largest bond distance have been elongated through relaxed scan calculations defining increments of $0.1 \AA$. The smaller $6-31 G^{*}$ basis set have been used to make the scan calculations affordable. Final energies have been subsequently recomputed using the $6-311 \mathrm{G}(\mathrm{d}, \mathrm{p})$ basis set, and the ${ }^{3} \mathrm{MLCT}$ or ${ }^{3} \mathrm{MC}$ nature of the state have been determined by computing the NTOs at each geometry. Scan calculations using the unrestricted (u)DFT method leads to extremely similar results as reported in the ESI (see Figure S21). On the other hand, the quintet ${ }^{5} \mathrm{MC}$ states have been calculated using the unrestricted DFT/HCTH ansatz.

The singlet-triplet SOCs $\left\langle\psi_{S}\left|\widehat{H}_{S O}\right| \psi_{T}\right\rangle$, where $\widehat{H}_{S O}$ refers to the spin-orbit Hamiltonian, have been computed using the ADF 2018 modelling suite, ${ }^{38,39,40}$ employing the TD-HCTH method and making use of the DZP basis set for all atoms except for iron, described with the TZP basis set.

\section{Femtosecond transient absorption spectroscopy}

The 800-nm output of a $5 \mathrm{kHz}$ Ti:Sapphire amplifier (Amplitude Technologies) is sent into a commercial optical parametric amplifier (TOPAS, Light Conversion) to obtain the pump beam at $480 \mathrm{~nm}$ (pulse duration of $\sim 60 \mathrm{fs}$ ). $0.4-0.5 \mathrm{~mW}$ average power (80-100 $\mu \mathrm{J}$ per pulse) is used to work in a regime of linear signal response. In order to generate the broadband white-light, a small portion of the initial $800 \mathrm{~nm}$ beam is focused onto a $\mathrm{CaF}_{2}$ crystal, mounted on a loudspeaker to prevent thermal degradation. The TA data and a reference beam are acquired in the range 350-680 $\mathrm{nm}$ using a Peltier-cooled charge-coupled device (CCD), which is operated at $220 \mathrm{~Hz}$ spectral read-out rate, and the exit of a $25-\mathrm{cm}$ focal length spectrometer (resolution $3 \mathrm{~nm}$ ). The polarization of pump and probe beams is set at the magic angle $\left(54.7^{\circ}\right)$ and both are focalised into the sample with a diameter of 60 and 40 $\mu \mathrm{m}$ respectively. The complexes are dissolved in $\mathrm{AcN}$ in a 1mm quartz cell (O.D. $\approx 0.3$ ). The transient absorption spectra of the complexes and the solvent are acquired. All of them are treated to correct for Group Velocity Dispersion (+/- $50 \mathrm{fs}$ ). The solvent data are subtracted (corrected with an appropriate factor 
in order to remove the Raman signals of $\mathrm{CH}_{3} \mathrm{CN}$ and the crossphase modulation artefacts (see ref. ${ }^{41}$ ). A detailed qualitative analysis of the spectra and the kinetics is performed. This is followed, when indicated, by Single Value Decomposition (SVD) and Global Analysis (using Glotaran, www.glotaran.org) for $\mathbf{C 4}$ and $\mathbf{C 2}$ while, for the others, single wavelength fits are made. In this case, a multi-exponential is convoluted by the temporal instrument response function (IRF), assumed to be a Gaussian, centred at $t=+/-50 \mathrm{fs}$, with $60 \mathrm{fs}$ FWHM (see SI).

\section{Conflicts of interest}

There are no conflicts to declare

\section{Acknowledgements}

The project is funded by the French Agence Nationale de Recherche (ANR-16-CE07-0013-02). The L2CM team is grateful to F. Lachaud for mass spectrometry. The Strasbourg team thanks O. Crégut, J. Brazard and J. Léonard for help and fruitful discussions. Molecular modelling has been performed on the LPCT local computing resources. A.F.-M. acknowledges the Région Grand Est government (France) and the ANR agency for postdoctoral contracts, and the MINECO project CTQ2017-87054-C2-2-P (Spain). The Strasbourg group acknowledges financial support through the Labex NIE.

This article is a proof of the LPCT team's recognition of JeanFrançois Hallet's accomplishments in the field of theoretical studies of transition metal compounds.

\section{References}

1 W. R. Browne and B. L. Feringa, Nat. Nanotechnol., 2006, 1, 25-35.

2 J. Kalinowski, V. Fattori, M. Cocchi and J. A. G. Williams, Coord. Chem. Rev., 2011, 255, 24012425.

3 B. Colasson, A. Credi and G. Ragazzon, Coord. Chem. Rev., 2016, 325, 125-134.

4 E. Longhi and L. De Cola, in Iridium(III) in Optoelectronic and Photonics Applications, ed. E. Zysman-Colman, John Wiley \& Sons, Ltd, Chichester, UK, 2017, pp. 205-274.

5 A. Hagfeldt, G. Boschloo, L. Sun, L. Kloo and H. Pettersson, Chem. Rev., 2010, 110, 6595-6663.

6 C. D. Clark, M. Z. Hoffman, D. Paul Rillema and Q. G. Mulazzani, J. Photochem. Photobiol. Chem., 1997, 110, 285-290.
7 W. Gawelda, A. Cannizzo, V.-T. Pham, F. van Mourik, C. Bressler and M. Chergui, J. Am. Chem. Soc., 2007, 129, 8199-8206.

8 J. K. McCusker, K. N. Walda, R. C. Dunn, J. D. Simon, D. Magde and D. N. Hendrickson, J. Am. Chem. Soc., 1993, 115, 298-307.

9 J. E. Monat and J. K. McCusker, J. Am. Chem. Soc., 2000, 122, 4092-4097.

10C. Consani, M. Prémont-Schwarz, A. ElNahhas, C. Bressler, F. van Mourik, A. Cannizzo and M. Chergui, Angew. Chem. Int. Ed., 2009, 48, 71847187.

110. S. Wenger, J. Am. Chem. Soc., 2018, 140, 13522-13533.

12Y. Liu, P. Persson, V. Sundström and K. Wärnmark, Acc. Chem. Res., 2016, 49, 14771485.

13T. Duchanois, L. Liu, M. Pastore, A. Monari, C. Cebrián, Y. Trolez, M. Darari, K. Magra, A. Francés-Monerris, E. Domenichini, M. Beley, X. Assfeld, S. Haacke and P. Gros, Inorganics, 2018, 6, 63 .

14L. Liu, T. Duchanois, T. Etienne, A. Monari, M. Beley, X. Assfeld, S. Haacke and P. C. Gros, Phys Chem Chem Phys, 2016, 18, 12550-12556.

15 M. Pastore, T. Duchanois, L. Liu, A. Monari, X. Assfeld, S. Haacke and P. C. Gros, Phys Chem Chem Phys, 2016, 18, 28069-28081.

16A. Francés-Monerris, K. Magra, M. Darari, C. Cebrián, M. Beley, E. Domenichini, S. Haacke, M. Pastore, X. Assfeld, P. C. Gros and A. Monari, Inorg. Chem., 2018, 57, 10431-10441.

17K. Magra, E. Domenichini, A. Francés-Monerris, C. Cebrián, M. Beley, M. Darari, M. Pastore, A. Monari, X. Assfeld, S. Haacke and P. C. Gros, Inorg. Chem., 2019, 58, 5069-5081.

18R. E. Andrew, L. González-Sebastián and A. B. Chaplin, Dalton Trans., 2016, 45, 1299-1305.

19A. A. Danopoulos, N. Tsoureas, J. A. Wright and M. E. Light, Organometallics, 2004, 23, 166-168. 20T. Duchanois, T. Etienne, C. Cebrián, L. Liu, A. Monari, M. Beley, X. Assfeld, S. Haacke and P. C. Gros, Eur. J. Inorg. Chem., 2015, 2015, 24692477.

21R. L. Martin, J. Chem. Phys., 2003, 118, 47754777. 
22J. J. Snellenburg, S. P. Laptenok, R. Seger, K. M. Mullen and I. H. M. van Stokkum, J. Stat. Softw., , DOI:10.18637/jss.v049.i03.

23T. Duchanois, L. Liu, M. Pastore, A. Monari, C. Cebrián, Y. Trolez, M. Darari, K. Magra, A. Francés-Monerris, E. Domenichini, M. Beley, X. Assfeld, S. Haacke and P. Gros, Inorganics, 2018, 6, 63-63.

24Y. Liu, T. Harlang, S. E. Canton, P. Chábera, K. Suárez-Alcántara, A. Fleckhaus, D. A. Vithanage, E. Göransson, A. Corani, R. Lomoth, V. Sundström and K. Wärnmark, Chem. Commun., 2013, 49, 6412.

25P. Chábera, K. S. Kjaer, O. Prakash, A. Honarfar,

Y. Liu, L. A. Fredin, T. C. B. Harlang, S. Lidin, J. Uhlig, V. Sundström, R. Lomoth, P. Persson and K. Wärnmark, J. Phys. Chem. Lett., 2018, 9, 459463.

26A. Rondi, Y. Rodriguez, T. Feurer and A. Cannizzo, Acc. Chem. Res., 2015, 48, 14321440.

27G. Roymahapatra, S. Giri, A. A. Danopoulos, P. K. Chattaraj, A. Mahapatra, V. Bertolasi and J. Dinda, Inorganica Chim. Acta, 2012, 383, 83-90. 28M. J. Frisch, G. W. Trucks, H. B. Schlegel, G. E. Scuseria, M. A. Robb, J. R. Cheeseman, G. Scalmani, V. Barone, B. Mennucci, G. A. Petersson, H. Nakatsuji, M. Caricato, X. Li, H. P. Hratchian, A. F. Izmaylov, J. Bloino, G. Zheng, J. L. Sonnenberg, M. Hada, M. Ehara, K. Toyota, R. Fukuda, J. Hasegawa, M. Ishida, T. Nakajima, Y. Honda, O. Kitao, H. Nakai, T. Vreven, J. A. Montgomery Jr., J. E. Peralta, F. Ogliaro, M. Bearpark, J. J. Heyd, E. Brothers, K. N. Kudin, V. N. Staroverov, R. Kobayashi, J. Normand, K. Raghavachari, A. Rendell, J. C. Burant, S. S. lyengar, J. Tomasi, M. Cossi, N. Rega, J. M. Millam, M. Klene, J. E. Knox, J. B. Cross, V. Bakken, C. Adamo, J. Jaramillo, R. Gomperts, R. E. Stratmann, O. Yazyev, A. J. Austin, R. Cammi, C. Pomelli, J. W. Ochterski, R. L. Martin, K. Morokuma, V. G. Zakrzewski, G. A. Voth, P. Salvador, J. J. Dannenberg, S. Dapprich, A. D. Daniels, O. Farkas, J. B. Foresman, J. V Ortiz, J. Cioslowski and D. J. Fox, Revis. D01, 2010, Gaussian Inc., Wallingford CT.
29P. Verma, Z. Varga, J. E. M. N. Klein, C. J. Cramer, L. Que and D. G. Truhlar, Phys Chem Chem Phys, 2017, 19, 13049-13069.

30B. D. Alexander, T. J. Dines and R. W. Longhurst, Chem. Phys., 2008, 352, 19-27.

31D. N. Bowman and E. Jakubikova, Inorg. Chem., 2012, 51, 6011-6019.

32S. Hirata and M. Head-Gordon, Chem. Phys. Lett., 1999, 314, 291-299.

33 A. D. Boese and N. C. Handy, J. Chem. Phys., 2001, 114, 5497-5503.

34T. Duchanois, T. Etienne, M. Beley, X. Assfeld, E. A. Perpète, A. Monari and P. C. Gros, Eur. J. Inorg. Chem., 2014, 2014, 3747-3753.

35R. L. Martin, J. Chem. Phys., 2003, 118, 47754777.

36T. Etienne, X. Assfeld and A. Monari, J. Chem. Theory Comput., 2014, 10, 3896-3905.

37T. Etienne, X. Assfeld and A. Monari, J. Chem. Theory Comput., 2014, 10, 3906-3914.

38ADF2018, SCM, Theoretical Chemistry, Vrije Universiteit, Amsterdam, The Netherlands, https://www.scm.com

39C. Fonseca Guerra, J. G. Snijders, G. te Velde and E. J. Baerends, Theor. Chem. Acc. Theory Comput. Model. Theor. Chim. Acta, 1998, 99, 391-403.

40G. te Velde, F. M. Bickelhaupt, E. J. Baerends, C. Fonseca Guerra, S. J. A. van Gisbergen, J. G. Snijders and T. Ziegler, J. Comput. Chem., 2001, 22, 931-967.

41T. Roland, J. Léonard, G. Hernandez Ramirez, S. Méry, O. Yurchenko, S. Ludwigs and S. Haacke, Phys Chem Chem Phys, 2012, 14, 273-279. 